\title{
Formation of cracks in layered rock considering layer thickness variations
}

\author{
Xu Chang, ${ }^{1,2}$ Jianyou Lu, ${ }^{1,2}$ Shanyong Wang, ${ }^{1,3}$ Shuren Wang ${ }^{1}$ and Xiliang Liu ${ }^{1}$ \\ ${ }^{1}$ International Joint Research Laboratory of Henan Province for Underground Space Development and Disaster Prevention, \\ Jiaozuo 454000, China.E-mail: changxu1980@hpu.edu.cn \\ ${ }^{2}$ School of Civil Engineering, Henan Polytechnic University, Jiaozuo 454000, China \\ ${ }^{3}$ ARC Centre of Excellence for Geotechnical Science and Engineering, Civil, Surveying and Environmental Engineering, \\ University of Newcastle, Callaghan, NSW 2308, Australia
}

Accepted 2017 June 19. Received 2017 May 21; in original form 2017 February 17

\begin{abstract}
SUMMAR Y
The formation mechanisms for layer interface-parallel discontinuities and their interactions with vertical cracks in layered rocks with varying layer thickness are investigated. The interface behaviour between rock layers is modeled by a shear displacement response and rock crack behaviour is described by a damage model. Three typical failures can be captured: (1) vertical cracking, (2) delamination and (3) interface-parallel cracking. The result further indicates these crack modes are determined by a threshold of the interfacial strength. When the interfacial strength is higher than the threshold, a combined pattern of vertical cracking and interfaceparallel cracking occurs. If the strength is lower than the threshold, a combined pattern of vertical cracking and interfacial delamination can be found. If the strength for the interface is near the threshold, a combined pattern of interface-parallel cracking, vertical cracking and interfacial delamination occurs. The result shows the interface-parallel discontinuities are induced by interface-delamination, interface-parallel cracks, or their coupling behaviour. Both interfacial delamination and interface-parallel cracking can reduce the tensile stress between two adjacent cracks and thus lead to a saturation state. Layer thickness variations can further influence the infilling process of vertical cracks and the crack spacing to average layer thickness ratios.
\end{abstract}

Key words: Fracture and flow; Geomechanics; Tectonics and landscape evolution.

\section{INTRODUCTION}

Cracks in layered sedimentary rocks are universal phenomena (Zhang \& Jeffrey 2006; Li \& Yang 2007; Engelder et al. 2009; Hooker et al. 2009, 2013; Noten \& Sintubin 2010; Ferrill et al. 2011; Riley et al. 2011, 2012; Gudmundsson et al. 2013; Hooker \& Katz 2015; Jesus et al. 2016). In some cases, these cracks are periodically distributed, equally spaced and parallel or subparallel to each other (Chang et al. 2011; Li et al. 2012). These crack networks can critically affect the stability for roadways and other underground openings built in sedimentary rocks. Therefore, better understanding of crack formation can help to improve stability analysis for cracked layer-sedimentary rocks.

Significant field observations, laboratory tests and numerical simulations have indicated that the crack spacing in layered rocks between two adjacent cracks is closely linked with the cracked layer thickness. Field statistics (Wu \& Pollard 1995; Gross \& Engelder 1995) have shown that crack spacing in rock sequences varies linearly with the layer thickness. Wu \& Pollard (1995) demonstrated the facture process in bending experiments. The experimental re- sults indicated that as the tensile load increased, the crack spacing decreased by crack nucleation and propagation. Eventually, the crack spacing was so small that no new cracks could further infill. Instead, the formed cracks became more open to suit the increasing load. The process of crack formation was named as crack infilling, while the point at which new cracks could not further infill was called saturation. The finite-element method was also adopted to explore the stress evolution between cracks by a three-layer model with a cracked interlayer (Bai et al. 2000). The numerical simulation indicated that with the cracking spacing to layered thickness ratio exceeded a threshold, the normal stress perpendicular to the cracks between two adjacent cracks changed from tension to compression. The stress evolution was considered to stop crack infilling.

Although cracking problem has been widely discussed, including the relationship between layer thickness and crack spacing, crack density and the mechanical explanation for crack infilling and saturation, two issues are needed to be further investigated. Most of the aforementioned studies focus on the layered rocks with constant layer thickness, effects of layer thickness variation on the formation 


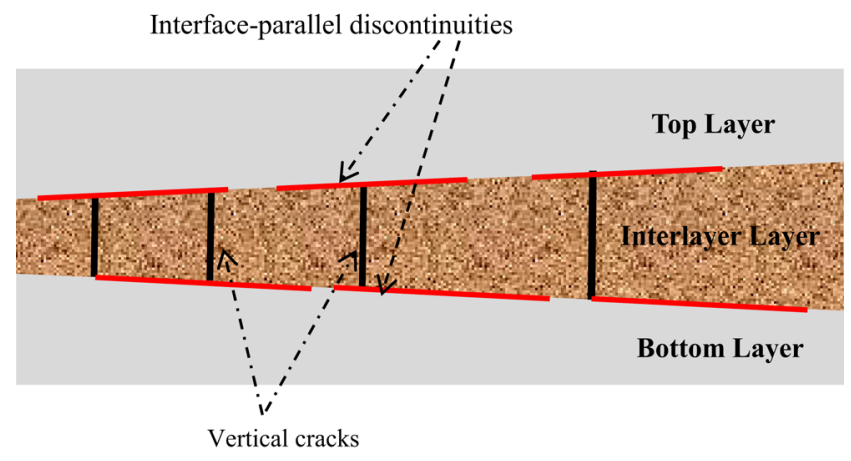

Figure 1. Sketch for vertical cracks and interface-parallel discontinuities in the layered rocks with varying layer thickness.

mechanism of cracks are still unclear. As sketched in Fig. 1, some discontinuities parallel to the layer interface can also been found in layered rocks, the formation of these parallel discontinuities and their interaction with the vertical cracks need to be further investigated. The term interface is defined as the bound between two adjacent layers.

\section{MODEL DESCRIPTION}

\subsection{Rock mass}

It is a challenging task to model propagation behaviour of multiple cracks in a continuous medium (Areias et al. 2016). Therefore, the continuous damage model has popularly adopted to analyse the crack behaviour of materials with multiple cracks (Shcherbakov \& Turcotte 2003). The damage model proposed by Lubliner et al. (1989) is adopted, which has been proposed for quasi-brittle materials, such as concrete and rock. In this model, the damage variables $(D)$ for materials under tension $\left(d_{t}\right)$ and compression $\left(d_{c}\right)$ are defined as follow.

For rock material in uniaxial tension, the stress-strain curve is sketched in Fig. 2(a) (ABAQUS 2009), a linear ascending branch up to $\sigma_{t 0}$ and then a softening branch. If the rock material is damaged due to rock cracking, the slope of the unloading path is reduced to $\left(1-d_{t}\right) E_{0} . d_{t}$ is the damage variable under tension. And in the softening branch, the cracking strain $\left(\varepsilon_{t}^{\mathrm{ck}}\right)$ can be expressed as:

$\varepsilon_{t}^{\mathrm{ck}}=\varepsilon_{t}-\varepsilon_{0 t}^{\mathrm{el}}$

where $\varepsilon_{t}$ is the tensile strain and $\varepsilon_{0 t}^{\mathrm{el}}$ can be obtained by $\varepsilon_{0 \mathrm{t}}^{\mathrm{el}}=\sigma_{t} / E_{0}$.

According to Fig. 2(a), the plastic strain can be expressed as:

$\varepsilon_{t}^{\mathrm{pl}}=\varepsilon_{t}^{\mathrm{ck}}-\frac{d_{t}}{\left(1-d_{t}\right)} \frac{\sigma_{t}}{E_{0}}$

where $d_{t}$ is damage variable under tension.

For rock mass in compressive state, the stress-strain curve is sketched in Fig. 2(b) (ABAQUS 2009). The evolution of the damage $\left(d_{c}\right)$, which is related to the plastic strain $\left(\varepsilon_{c}^{\mathrm{pl}}\right)$, could be described as:

$\varepsilon_{c}^{\mathrm{pl}}=\varepsilon_{c}^{\mathrm{ie}}-\frac{d_{c}}{\left(1-d_{c}\right)} \frac{\sigma_{c}}{E_{0}}$

where $\sigma_{c}$ and $\varepsilon_{c}^{\mathrm{pl}}$ are the compressive stress and compressive strain after the elastic limit, respectively. $E_{c}$ is the Young's modulus. $\varepsilon_{c}^{\text {ie }}$ is the inelastic strain. According to Fig. 2(b), the inelastic strain can be obtained by $\varepsilon_{c}^{\mathrm{ie}}=\varepsilon_{c}-\varepsilon_{0 c}^{\mathrm{el}}$ and $\varepsilon_{0 c}^{\mathrm{el}}=\sigma_{c} / E_{0}$.
Therefore, the stress-strain relations can be further expressed as:

$\left\{\begin{array}{l}\sigma_{t}=\left(1-d_{t}\right) E_{0}\left(\varepsilon_{t}-\varepsilon_{t}^{\mathrm{pl}}\right) \\ \sigma_{c}=\left(1-d_{c}\right) E_{0}\left(\varepsilon_{c}-\varepsilon_{c}^{\mathrm{pl}}\right)\end{array}\right.$

According to eqs (2) and (3), the damage variables for rock under tension and compression can be described as:

$d_{t}=1-\frac{\sigma_{t} E_{0}^{-1}}{\varepsilon_{t}^{\mathrm{pl}}\left(\varepsilon_{t}^{\mathrm{pl}} / \varepsilon_{t}^{\mathrm{ck}}-1\right)+\sigma_{t} E_{0}^{-1}}$
$d_{c}=1-\frac{\sigma_{c} E_{0}^{-1}}{\varepsilon_{c}^{\mathrm{pl}}\left(\varepsilon_{c}^{\mathrm{pl}} / \varepsilon_{c}^{\mathrm{ie}}-1\right)+\sigma_{c} E_{0}^{-1}}$

The effective tensile and compressive stress can be defined as (ABAQUS 2009):

$\left\{\begin{array}{l}\sigma_{t}^{\mathrm{ef}}=\frac{\sigma_{t}}{\left(1-d_{t}\right)}=E_{0}\left(\varepsilon_{t}-\varepsilon_{t}^{\mathrm{pl}}\right) \\ \sigma_{c}^{\mathrm{ef}}=\frac{\sigma_{c}}{\left(1-d_{c}\right)}=E_{0}\left(\varepsilon_{c}-\varepsilon_{c}^{\mathrm{pl}}\right)\end{array}\right.$

The yield surface is determined by effective plastic strains, $\varepsilon_{c}^{\mathrm{pl}}$ (under compressive condition) and $\varepsilon_{t}^{\mathrm{pl}}$ (under tensile condition). The yield function is (Lubliner et al. 1989):

$$
\begin{aligned}
F\left(\sigma^{\mathrm{ef}}, \varepsilon^{\mathrm{pl}}\right)= & \frac{1}{1-\zeta}\left(q-3 p \zeta+\beta\left(\varepsilon^{\mathrm{pl}}\right)\left\langle\sigma_{\max }^{\mathrm{ef}}\right\rangle\right) \\
& -\frac{1}{1-\zeta} \gamma\left\langle\sigma_{\max }^{\mathrm{ef}}\right\rangle-\sigma_{c}^{\mathrm{ef}}\left(\varepsilon_{c}^{\mathrm{pl}}\right) \leq 0
\end{aligned}
$$

with

$\zeta=\frac{\left(\sigma_{b 0} / \sigma_{c 0}\right)-1}{2\left(\sigma_{b 0} / \sigma_{c 0}\right)-1}, \quad(0 \leq \zeta \leq 0.5)$

$\beta\left(\varepsilon^{\mathrm{pl}}\right)=\frac{\sigma_{c}^{\mathrm{ef}}\left(\varepsilon_{c}^{\mathrm{pl}}\right)}{\sigma_{t}^{\mathrm{ef}}\left(\varepsilon_{t}^{\mathrm{pl}}\right)}(1-\zeta)-(1+\zeta)$

$\gamma=\frac{3\left(1-K_{c}\right)}{2 K_{c}-1}$

where $\zeta$ and $\gamma$ are constants; $\sigma_{b 0}$ is the initial equibiaxial compressive yield stress and $\sigma_{c 0}$ is the initial uniaxial compressive yield stress; $\sigma_{\max }^{\text {ef }}$ and $K_{c}$ are related to the maximum principal stress and the yield surface, respectively. $q$ and $p$ are the equivalent stress and the hydrostatic pressure.

The non-associated potential plastic flow is adopted for the damaged model (Lubliner et al. 1989). The flow potential $G$ adopted in this model is the Drucker-Prager hyperbolic function:

$G=\sqrt{\left(\prod \sigma_{t 0} \tan \phi^{2}\right)+q^{2}}-p \tan \phi$

where $\prod$ is typical value for quasi-brittle materials, $\phi$ is the dilation angle and $\sigma_{t 0}$ is the uniaxial tensile stress at failure.

The materials parameters used in this study are listed in Table 1. According to eqs (1)-(7), the damage variables can be obtained. Examples for evolutions of damage variables are illustrated in Figs 2(c) and (d).

\subsection{Layer interface}

In the existing studies, several models are suggested to model the interaction between different materials. The common assumption 


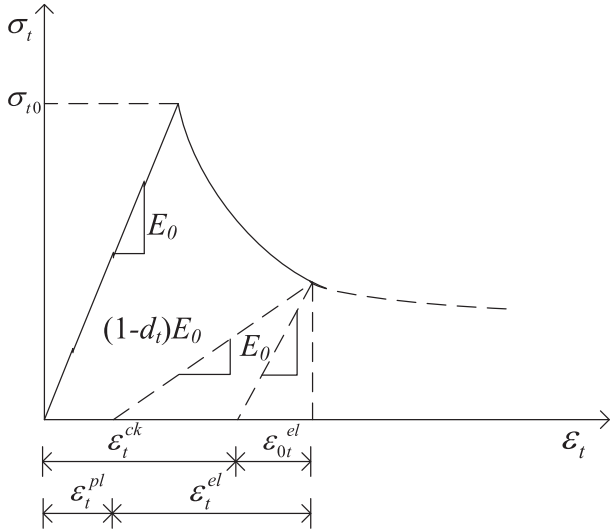

(a)

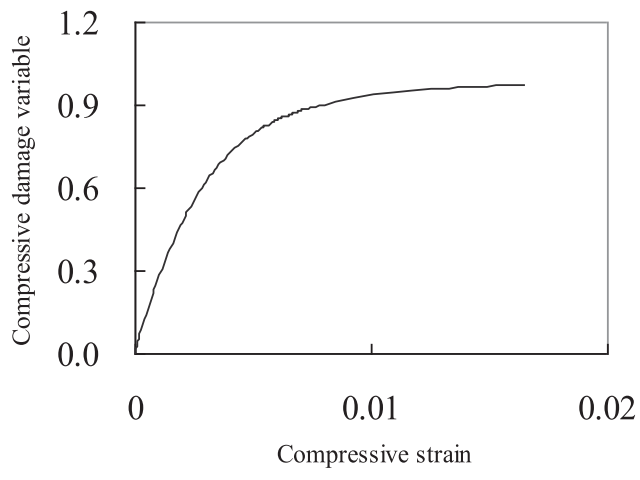

(c)

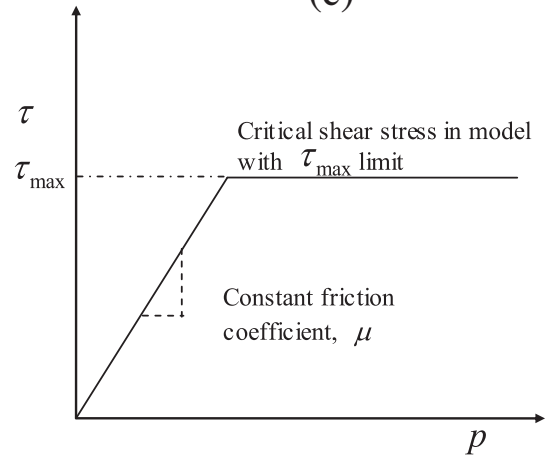

(e)

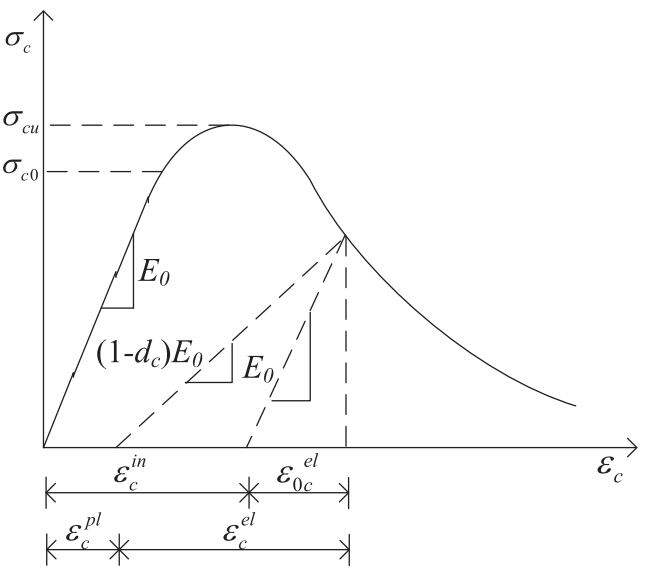

(b)

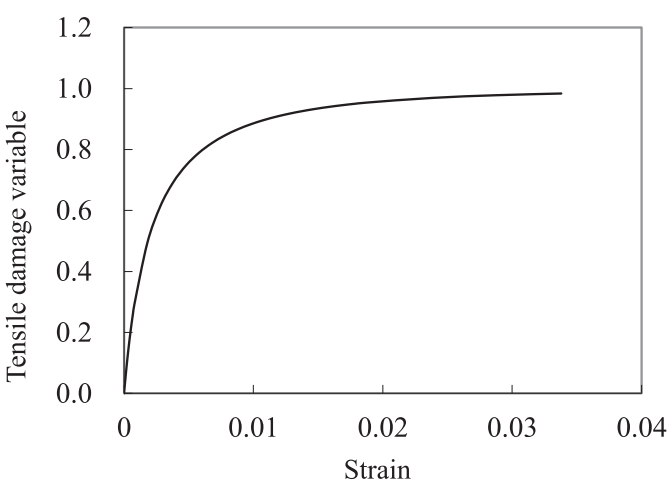

(d)

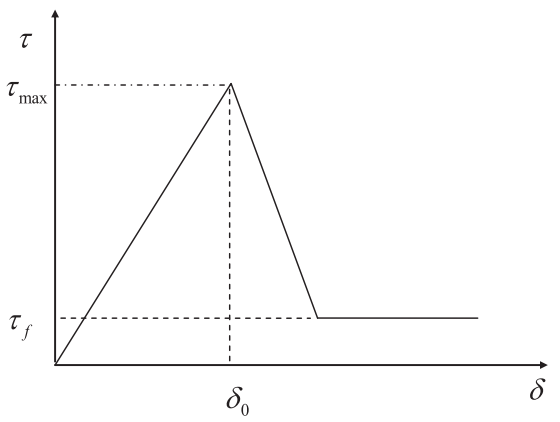

(f)

Figure 2. Material model: (a) damage variable for rock materials under tension; (b) damage variable for rock materials under compression; (c) evolution of the damage variables in compression; (d) evolution of the damage variables in tension; (e) Coulomb friction model for the interface; (f) trilinear model for the interface, where $\tau$ and $\delta$ are the shear stress and interface relative displacement; $\tau_{\max }$ and $\delta_{0}$ are the shear strength and the corresponding displacement and $\tau_{f}$ is the residual shear strength.

for the rock layers is that the layers are well bonded no slip is considered. The friction model is another common method to describe the interface behaviour between layers (shown in Fig. 2e). However, the interfacial shear stress is assumed to be constant after complete delamination. And the friction model therefore fails to obtain the interfacial stress decrement. In recent years, the cohesive zone model (CZM) pioneered by Dugdale (1960) has been widely used to capture the interaction between two materials, due to its simple formulation and convenience of application in numerical simulations (Wang 2006; Oded 2008). In this paper, the CZM is also introduced to model the interaction between rock layers. In the direction parallel to the layers, the properties of the CZM are defined by a traction model. A trilinear $\tau-\delta$ relationship is adopted in this study, as shown in Fig. 2(f). If the ascending response arrives at the shear strength $\left(\tau_{\max }\right)$, a linear softening response occurs, and then a horizontal branch follows, which represents the non-zero residual interfacial stress after delamination. The residual interface stress can be determined by

$\tau_{r}=\beta \tau_{\max }$

where $\beta$ is named as residual stress factor. 
Table 1. Material parameters for the damaged model.

\begin{tabular}{lcc}
\hline Parameters & Interlayer & Adjacent layer \\
\hline Elastic modulus $(\mathrm{GPa})$ & 48.0 & 13.0 \\
Compressive initiate strength $(\mathrm{MPa})$ & 61.0 & 39.0 \\
Compressive ultimate strength $(\mathrm{MPa})$ & 88.0 & 59.0 \\
Tensile strength & 7.3 & 5.9 \\
Poisson ratio & 0.20 & 0.25 \\
Density $\left(\mathrm{g} \mathrm{cm}^{-3}\right)$ & 2.2 & 1.9 \\
Dilation angle $\left(^{\circ}\right)$ & 36.0 & 36.0 \\
\hline
\end{tabular}

\section{RESULTS}

\subsection{Stress distribution between two adjacent vertical cracks}

A three-layer model with pre-assigned cracks is used (Fig. 3a) and the thickness varies linearly laterally. To facilitate discussion, a Cartesian coordinate system is used. The $x$-axis is horizontal and through the middle point of the two vertical boundaries and the $y$-axis is vertical. The interactions between different layers are
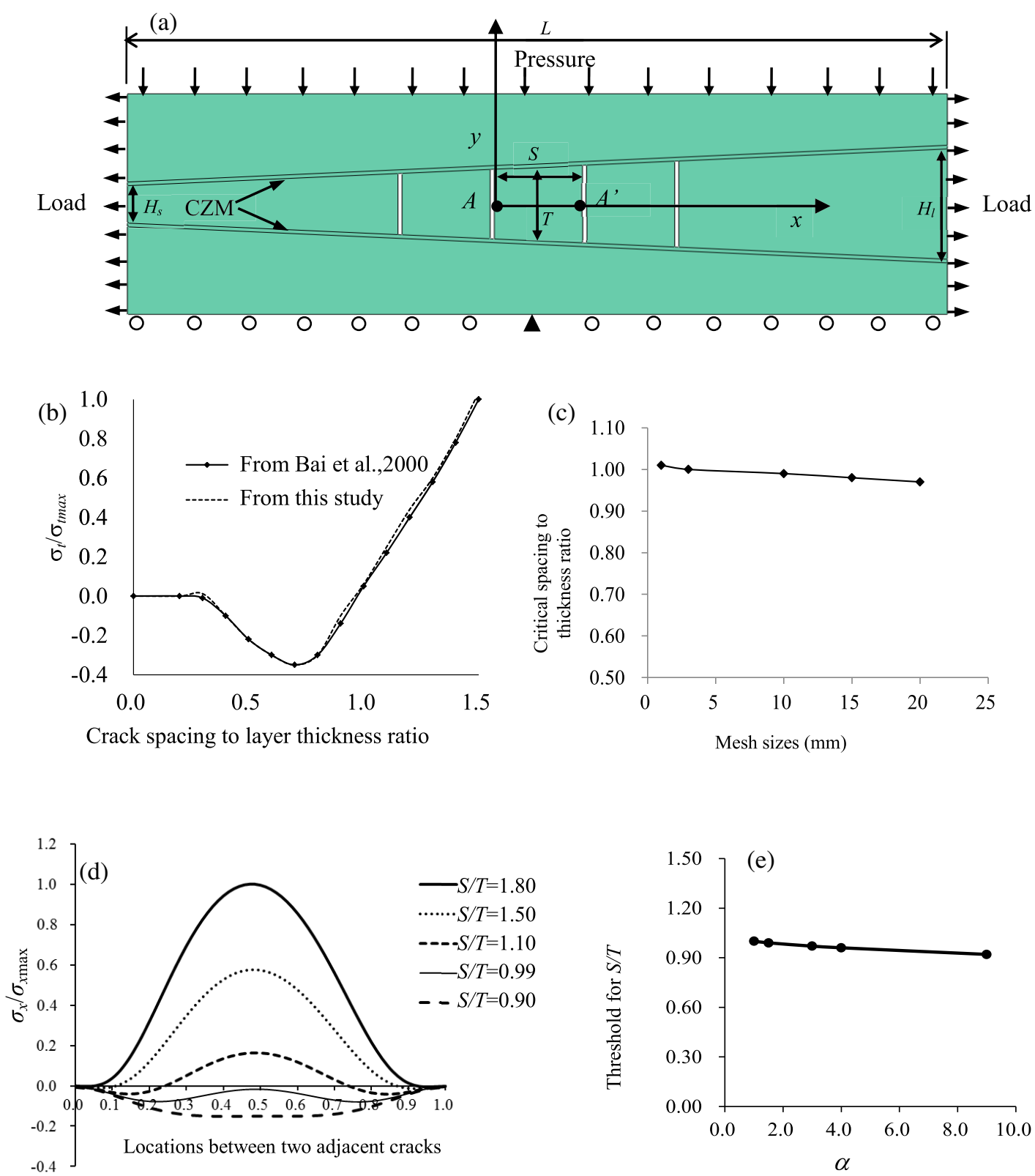

Figure 3. Stress distribution between two adjacent cracks. (a) model developed in this study for layered rocks. The $x$-axis is parallel to the layer top and bottom boundaries and perpendicular to the cracks. The bottom boundary is fixed in the $y$-direction, with the middle point fixed in the $x$-direction as well. Tensile loads are imposed on the left and right-hand sides of the model, and pressure is applied on the top. (b) Compared with the results by Bai et al. (2000) and those from this study for $\alpha=1.0$. Tensile stresses are positive, and compressive stresses are negative. (c) Effects of mesh sizes and (d) stress distribution between two adjacent cracks for layered rocks for $\alpha=2.5$. (e) Effects of $\alpha$ on threshold for $S / T$. 


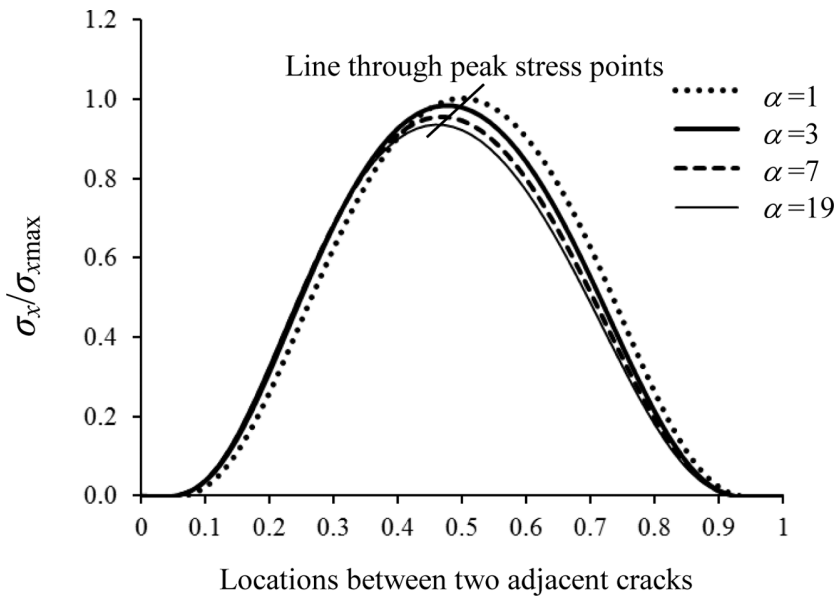

Figure 4. Effects of the variation coefficient of layer thickness on the stress distribution between two adjacent cracks.

modeled as cohesive zones. To describe the variation in layer thickness, a variation coefficient is defined as:

$\alpha=\frac{H_{l}}{H_{s}}$

where $H_{l}$ is the height of the right of the interlayer and $H_{s}$ is the height of the left-hand side. The model degrades to the model with constant layer thickness proposed by Bai et al. (2000) for the case of $\alpha=1.0$. The average interlayer thickness $\left(T=\left(H_{l}+H_{s}\right) / 2\right)$ is $T=20 \mathrm{~mm}$, and the model thickness is $80 \mathrm{~mm}$. The model bottom is fixed vertically and the horizontal degree of freedom of its middle point is also fixed. Tensions are then loaded on the left and righthand sides. Following Bai et al. (2000), a constant pressure of $5 \mathrm{MPa}$ is applied on the top of the model. The material parameters are listed in Table 1, which are also the same as those adopted in the previous studies (Bai et al. 2000). As an attempt to explore the formation mechanism of cracks in layered rocks with varying layer thickness, the evolution of the stress distribution between two adjacent vertical cracks is examined with various crack spacing $(S)$ to the average cracked layer thickness ratios $(S / T)$.

In previous studies (Bai et al. 2000; Tang et al. 2008; Li et al. 2012), the layer interfaces are assumed to be perfectly welded. For comparison purposes, the high value of shear strength $(18 \mathrm{MPa})$ for the interface is therefore adopted to preclude the interface delamination, and $\alpha=1.0$ is adopted. The stress values are quite different at different load levels. For ease of reference and discussion, the normalized stresses are adopted in this paper. As presented in Fig. 3(b), the normalized stress $\left(\sigma_{x} / \sigma_{x \max }\right)$ at the midpoint of line A $-\mathrm{A}^{\prime}$ varies with different crack spacing to cracked layer thickness ratios $(S / T)$. This indicates that the threshold value for $S / T$ is about 1.0. The threshold controls the stress distribution in a crack-bound block: if $S / T$ is less than the threshold, the stress along the given line is compressive. When $S / T$ is greater than the threshold, the normal stress is tensile. The results are in good agreement with those by Bai et al. (2000), as indicated in Fig. 3(b). After numerical modeling using a series of mesh sizes, it is found that a mesh size of $2 \mathrm{~mm}$ for the layer and cohesive zone is adequate to obtain sufficiently accurate result (threshold value for $S / T$ is about 1.0 equal to 1.0 ) and relatively acceptable computing time (Fig. 3c).

Fig. 3(d) presents the plot of $\sigma_{x} / \sigma_{x \max }$ along the given line versus $S / T$ for the case of $\alpha=2.5$. It can be seen in the figure that a threshold also exists for $S / T$, which controls the stress state between two adjacent cracks. With decreasing $S / T$, the tensile stress reduces gradually and eventually changes to compressive stress at the critical $S / T$ value of 0.98 . It can be seen that the evolution of stress distribution between two adjacent cracks for varying layer thickness is similar to that for constant layer thickness. Fig. 3(e) presents the plot of threshold for $S / T$ versus $\alpha$. It can be seen that the threshold decreases slowly by increasing the value of $\alpha$.

The influences of the variation coefficient $\alpha$ on the stress distribution between two adjacent cracks are presented in Fig. 4. The peak stress appears exactly at the middle point of line $\mathrm{AA}^{\prime}$ for the
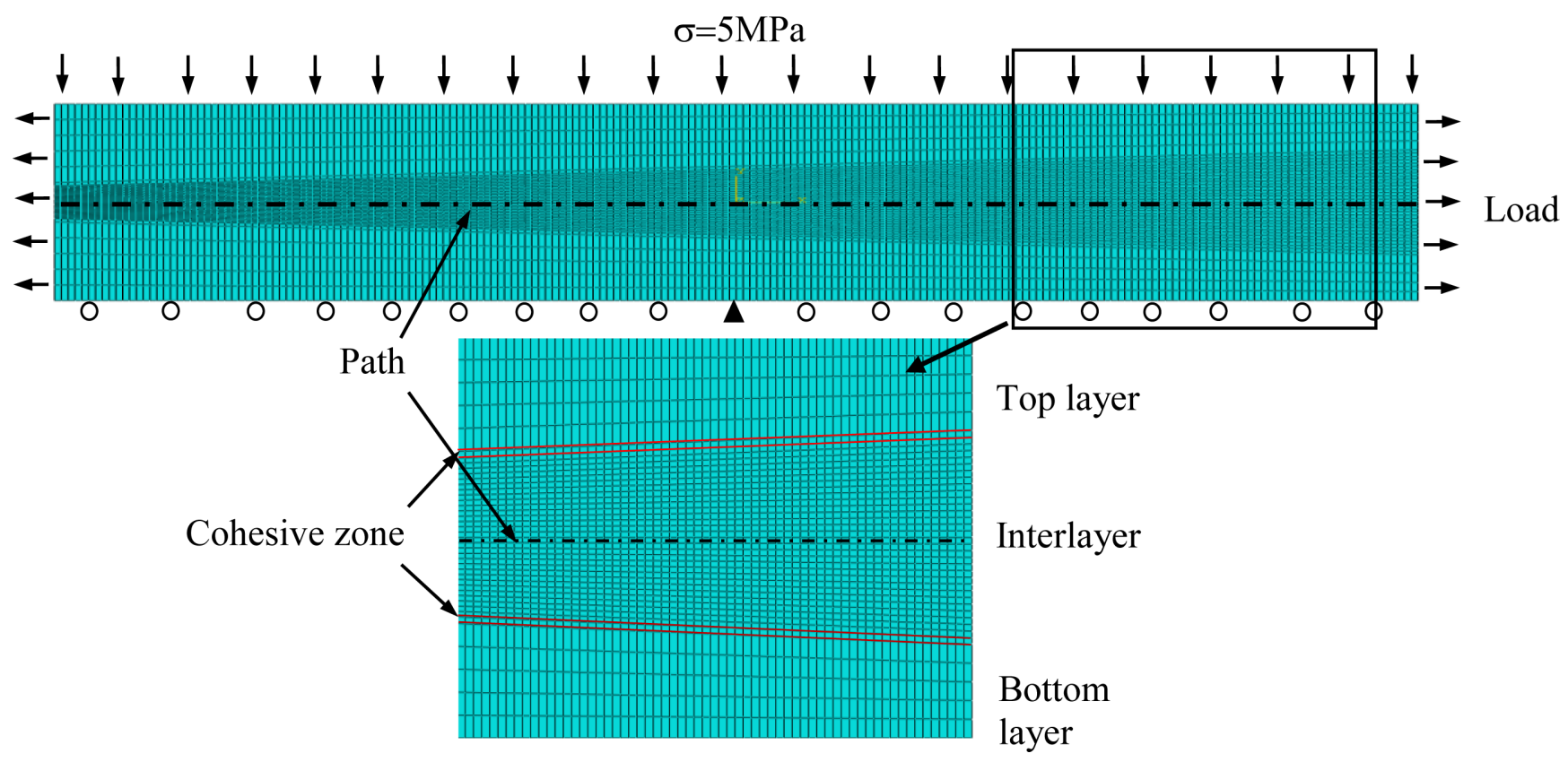

Figure 5. Element mesh and boundary conditions for the three-layer rock system with an overburden of $5 \mathrm{MPa}$. 
Table 2. Parameters for system with pre-assigned model (from Bai et al. 2000).

\begin{tabular}{lcc}
\hline Layer level & Poisson's ratio & Young's modulus (GPa) \\
\hline Top and bottom layers & 0.2 & 40 \\
Interlayer & 0.2 & 40 \\
\hline
\end{tabular}

case of $\alpha=1.0$. This means that the infilling crack may initiate at the middle location between two adjacent cracks. However, the peak stress deviates from the middle point and moves towards the left crack as the variation coefficient $\alpha$ increases. Therefore, it can be concluded that the infilling crack will appear close to the left crack.

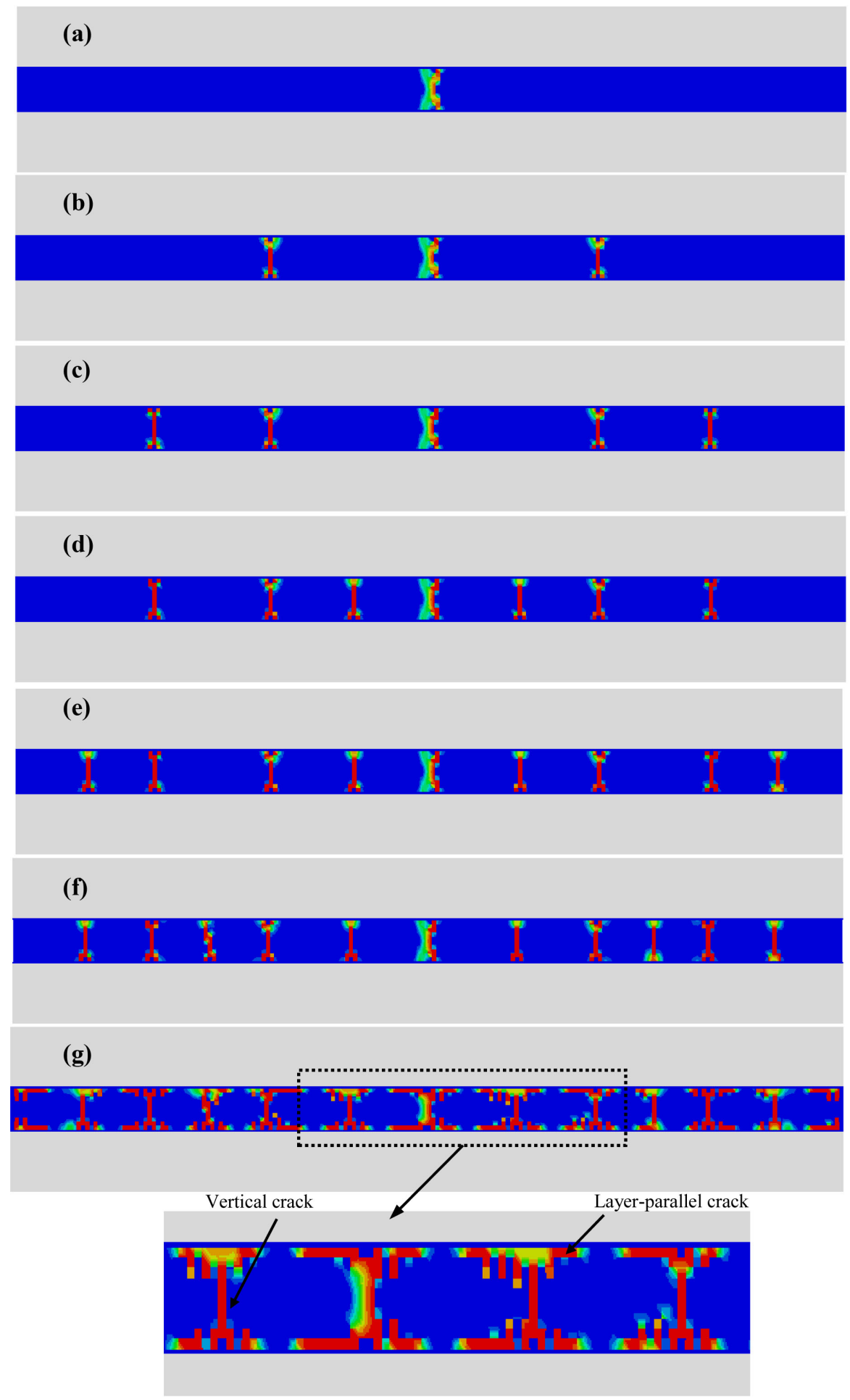

Figure 6. Cracking process for pattern I for $\alpha=1.0$. The interface shear strength is higher than the threshold, and vertical cracking and interface-parallel cracking can be observed. The different colours in the figures represent different values of damage variable (ranging from zero to one) of the individual element. 


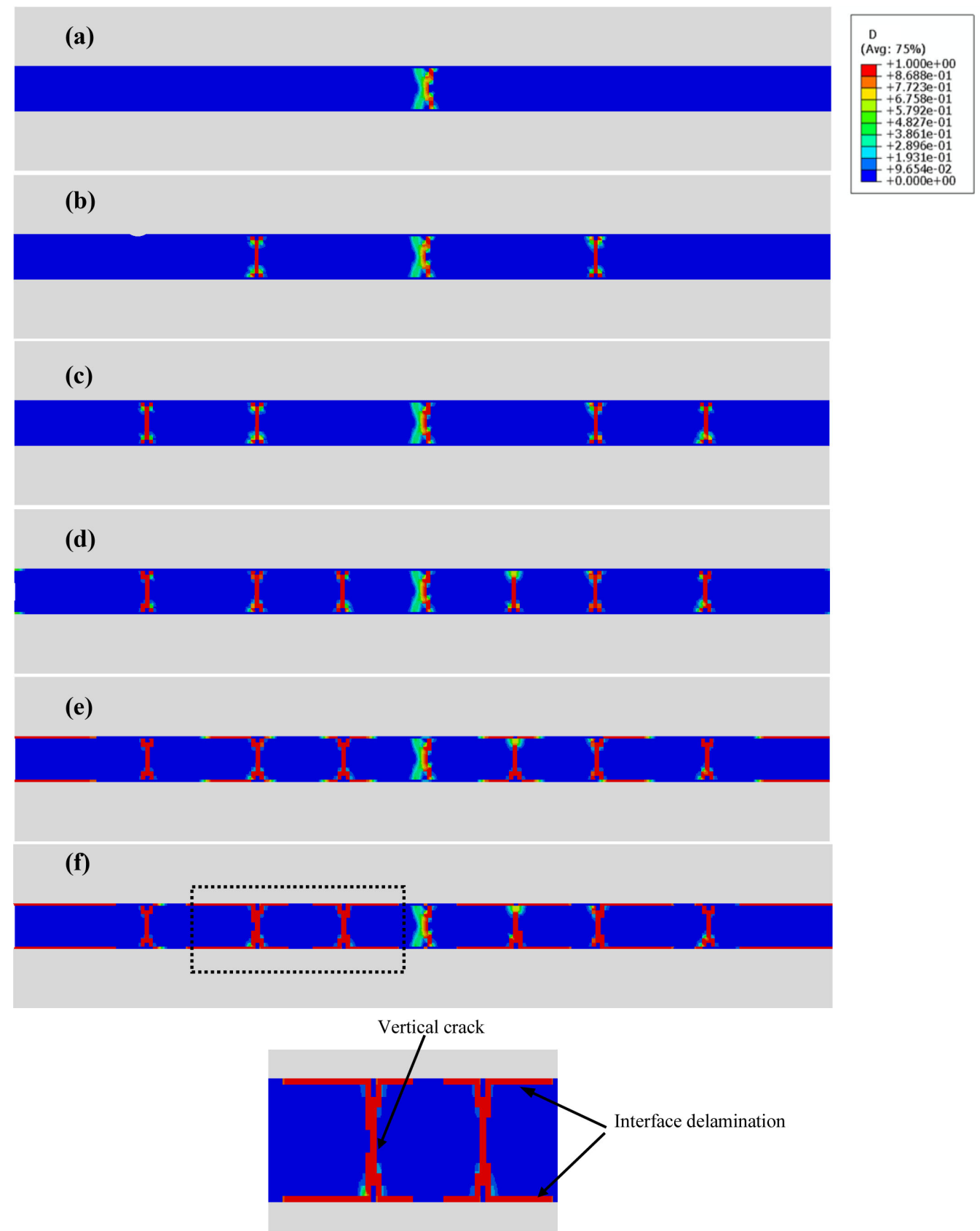

Figure 7. Cracking process for pattern II for $\alpha=1.0$. The interface shear strength is less than the threshold, and vertical cracking and interfacial delamination can be observed.

\subsection{Crack formation for $\alpha=1.0$}

In this section, the crack process of the layered rocks without any pre-assigned cracks is investigated for the case of $\alpha=1.0$. The materials parameters are listed in Table 1 . The residual strength factor is taken as 0.1 . The same three-layer rock system without pre-assigned cracks is used to model the crack process, as indicated in Fig. 5.

To study the influences of the interfacial shear strength on the crack process of the layered system, various values from 0 to $20 \mathrm{MPa}$ are used in this section, and the other parameters are kept constant as those in Table 2. The three typical crack patterns of the layered rocks are a combined pattern of vertical cracking and interface-parallel cracking (pattern I), a combined pattern of vertical cracking and interface delamination (pattern II) and a combined pattern of vertical cracking, interface-parallel cracking and interface delamination (pattern III). The numerical results show that a threshold exists for the interface shear strength which determines the crack patterns. When the shear strength is much higher than the threshold, the interlayer is meshed by the vertical cracks and interface-parallel cracks, which is pattern I. When the shear strength is sufficiently less than the threshold, pattern II occurs. If the strength is close to the threshold, pattern III can be observed. The typical failure processes for these three patterns are indicated in Figs 6-8. In these figures, the models are coloured for the evolution of the damage variables $(D$, ranging from 0 to 1$)$. The cracking spacing $(S)$ varies as the new crack continuously form during the cracking process. The evolutions of $S / T$ for these typical cracking patterns are 


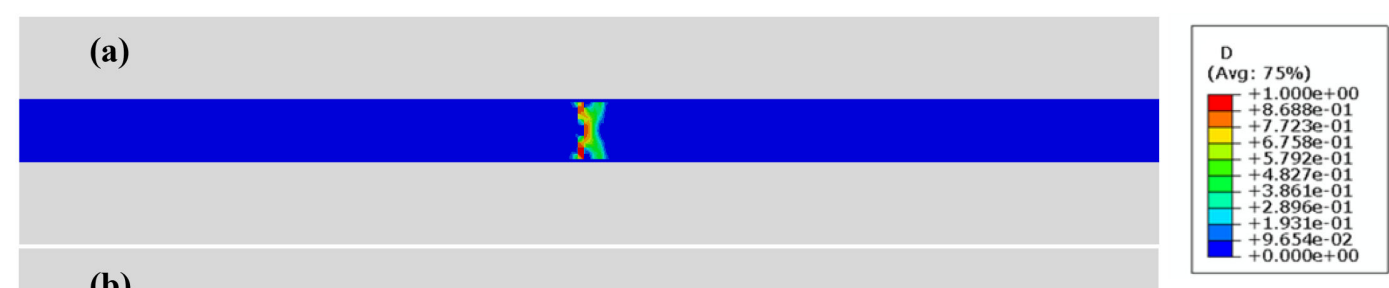

(b)

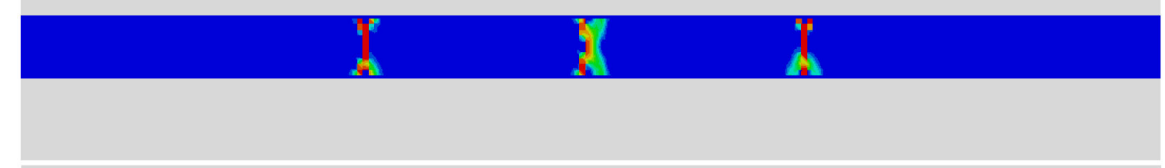

(c)

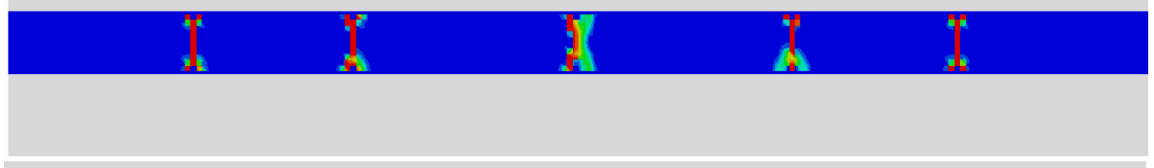

(d)

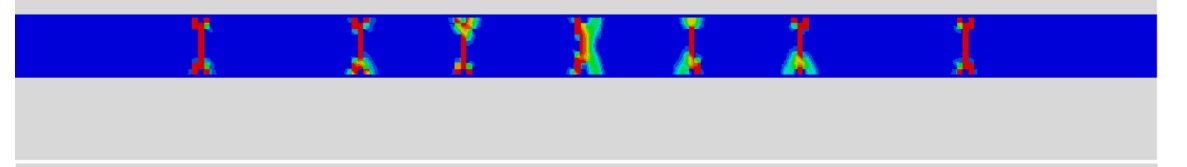

(e)

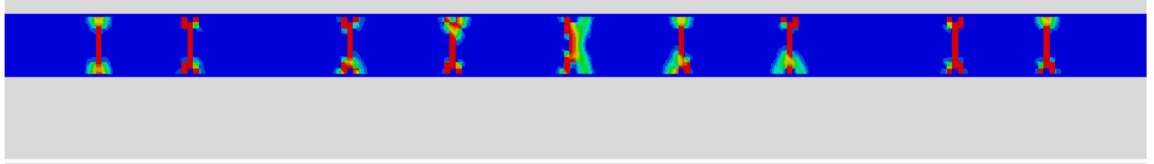

(f)
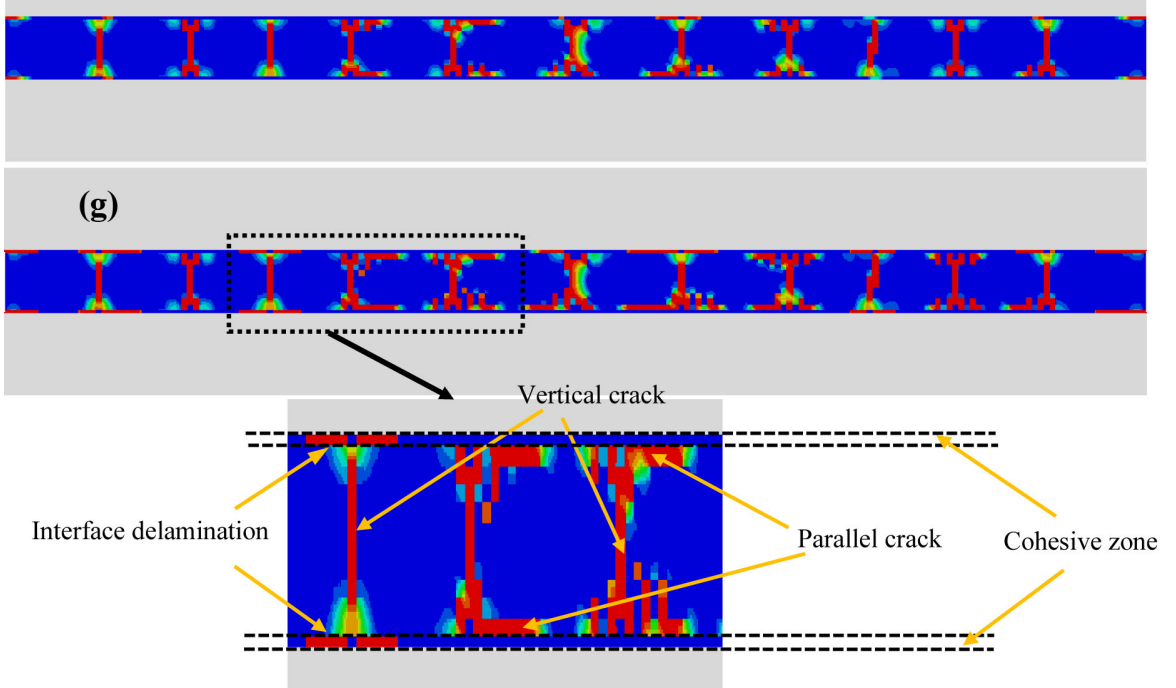

Figure 8. Cracking process for pattern III for $\alpha=1.0$. The interface shear strength is close to the threshold, and vertical cracking, interface-parallel cracking and interface delamination can be observed. The difference between interface-parallel cracking and interfacial delamination is that interface delamination occurs in the cohesive zone.

presented in Fig. 9. For each case, $S / T$ decreases as the external load increases. As the $S / T$ decreases to a certain value, it is kept constant even further increasing the tensile strain, which indicates the crack saturation.

Fig. 6 illustrates the numerically obtained crack process for pattern I ( shear strength $=16.0 \mathrm{MPa}$ ). According to the crack sequence, the whole process consists of different phases. First (Figs 6a-f), the vertical cracks form, and then the new vertical cracks infill between two adjacent cracks by increasing the external load. It can be seen that the infilling cracks appear symmetrically on both sides of the first vertical crack (Figs 6b-f). After the infilling process, no more cracks can further form (Fig. 6f). It should be noted that the crack infilling process is the same as that observed by Li et al. (2012). In the following phase (Fig. 6g), the interface-parallel cracks initiate 


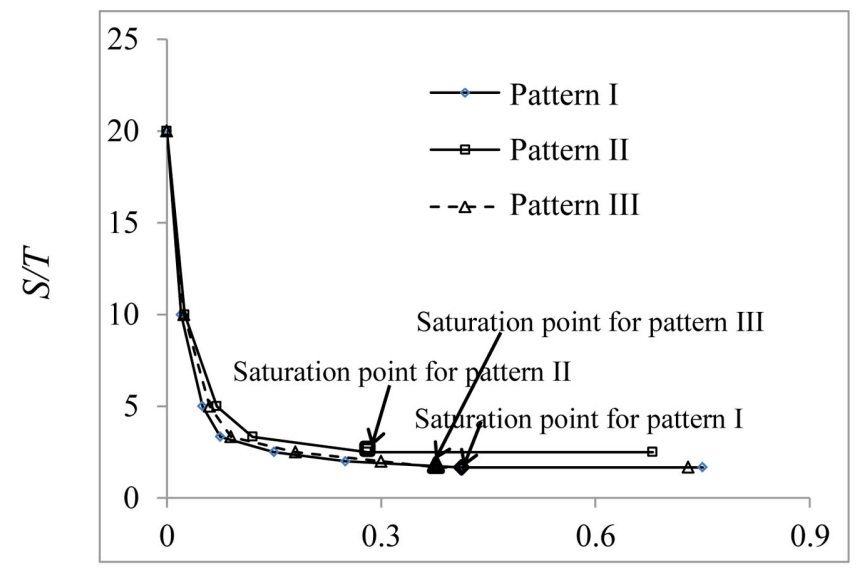

Tensile strain (\%)

Figure 9. $S / T$ varies by increasing tensile strain during the cracking process. It can be seen that $S / T$ is constant after saturation point for each case.

at the ends of vertical crack and propagate symmetrically to both sides of the vertical crack in the interlayer. Finally, the interlayer is divided into many grids by the vertical and interface-parallel cracks. It should be noted that no vertical crack forms in the second phase. For this case, no interfacial delamination could be found (Fig. 6g).

For pattern II (shear strength $=3.0 \mathrm{MPa}$ ), the vertical cracking and interfacial delamination are the dominating failures (Fig. 7). Similar to pattern I, the vertical cracks infill first (Figs 7a-d). Due to stress concentration, interfacial delamination then initiates near the tips of the vertical cracks and then propagates in cohesive zone. Once interfacial delamination occurs, no more vertical cracks can infill. This indicates that the initiation of interfacial delamination indicates the state of saturation. For this crack pattern, no interface-parallel cracks can be observed, as indicated in Fig. 7(f).

For pattern III (shear strength $=7.6 \mathrm{MPa}$ ), the whole cracking process could also be separated into two phases, as shown in Fig. 8 . In the first phase (Figs $8 \mathrm{a}-\mathrm{e}$ ), the vertical cracks infill continuously until reaching the saturation state. This is similar to patterns I and II. In the second phase, however, both interfacial delamination and interface-parallel cracking can nucleate and develop by increasing the applied load (shown in Figs $8 \mathrm{f}-\mathrm{g}$ ). It should be noted that the interfacial delamination and interface-parallel cracking are quite different, as compared in Fig. 8(g). The interfacial delamination occurs in the cohesive zone, while the interface-parallel crack initiates and propagates in the interlayer.

\subsection{Crack formation process for $\alpha=3.0$}

The typical crack formation processes for the three-layer system with varying layer thickness are presented in Figs 10-12. The variation coefficient, $\alpha$ is 3.0, and other material parameters for the three layers are the same as those listed in Table 2. With varying interface shear strength, the typical crack patterns of layered systems are similar: a combined pattern of vertical cracking and interface-parallel cracking (pattern I), a combined pattern of vertical cracking and interface delamination (pattern II) and a combined pattern of vertical cracking, interface-parallel cracking and interface delamination (pattern III). In addition, these crack patterns are also determined by the threshold for interfacial shear strength.
Fig. 10 gives the numerically obtained crack process for pattern I (shear strength $=15.0 \mathrm{MPa}$ ). It can be seen that the vertical cracks form first (Figs 10a-c) in sequence, from left to right. And then the new vertical cracks infill between two adjacent cracks by increasing the tensile strain (Figs 10d-g). It can be seen that the infilling cracks appear in the same order from left to right. In the following phase (Figs $10 \mathrm{~h}-\mathrm{j}$ ), the cracks parallel to the layer interface initiate at the ends of vertical cracks and propagate in the interlayer near the interface. These interface-parallel cracks first propagate right towards the adjacent vertical cracks and then left to the other adjacent vertical cracks. During the forming process of interface-parallel cracks, vertical cracks can also infill simultaneously. The interlayer is ultimately divided into many grids by the vertical and interface-parallel cracks. It should be noted that no interfacial delamination could be found (Fig. 10j). According to the cracking process, the differences for $\alpha=1.0$ and 3.0 lie in three aspects:

(1) For $\alpha=1.0$, vertical cracks appear symmetrically. For $\alpha=$ 3.0, the vertical cracks form in sequence, first in the thin parts of layers and then in the thick parts.

(2) For $\alpha=1.0$, interface-parallel cracks propagate from the ends of the vertical cracks symmetrically. For $\alpha=3.0$, however, the interface-parallel cracks propagate first to the right-hand side and then to the left-hand side.

(3) For $\alpha=1.0$, no vertical cracks can further infill during the formation of interface-parallel cracks. However, the infilling cracks and interface-parallel cracks can appear simultaneously for $\alpha=3.0$.

Fig. 11 gives the numerically obtained crack process for pattern II (shear strength $=3.0 \mathrm{MPa}$ ). It can be seen that the vertical cracks form first (Figs 11a-c) in sequence, from left to right. And then the new vertical cracks infill between two adjacent cracks by increasing the external load (Figs 11d-g). It can be seen that the infilling cracks appear in the same order from left to right. In the following phase (Figs $11 \mathrm{~h}-\mathrm{j}$ ), the interfacial delamination first propagate right from the tips of the vertical crack towards the adjacent vertical crack and then to the left adjacent vertical crack. During the propagation of the interfacial delamination, vertical cracks can also infill simultaneously. It can be seen that the formation of vertical cracks and propagation of interface delamination for $\alpha=3.0$ are also different from those for $\alpha=1.0$. The interface delamination for $\alpha=3.0$.

For pattern III (shear strength $=7.3 \mathrm{MPa}$ ), the whole cracking process could also be separated into two phases, as shown in Fig. 12. The vertical cracks appear continuously and the forming order of the vertical cracks is similar to patterns I and II. In the following phase, however, both interfacial delamination and interface-parallel cracking can be founded by increasing the applied load (shown in Figs $12 \mathrm{e}$ and $\mathrm{f}$ ).

\subsection{Stress evolution during the cracking process for $\alpha=3.0$}

To further understand the stress evolution during the crack process, a path along the central line of the interlayer is defined, as indicated in Fig. 5. The evolutions of the stress along the path and interfacial shear stress for the three typical cases are presented in Figs 13-15, where tensile and shear stresses are normalized by their maximum values.

For pattern I, once a vertical crack forms, the tensile stress at this point would drop to zero, and then interface shear stress develops between the two adjacent vertical cracks. Between two adjacent 


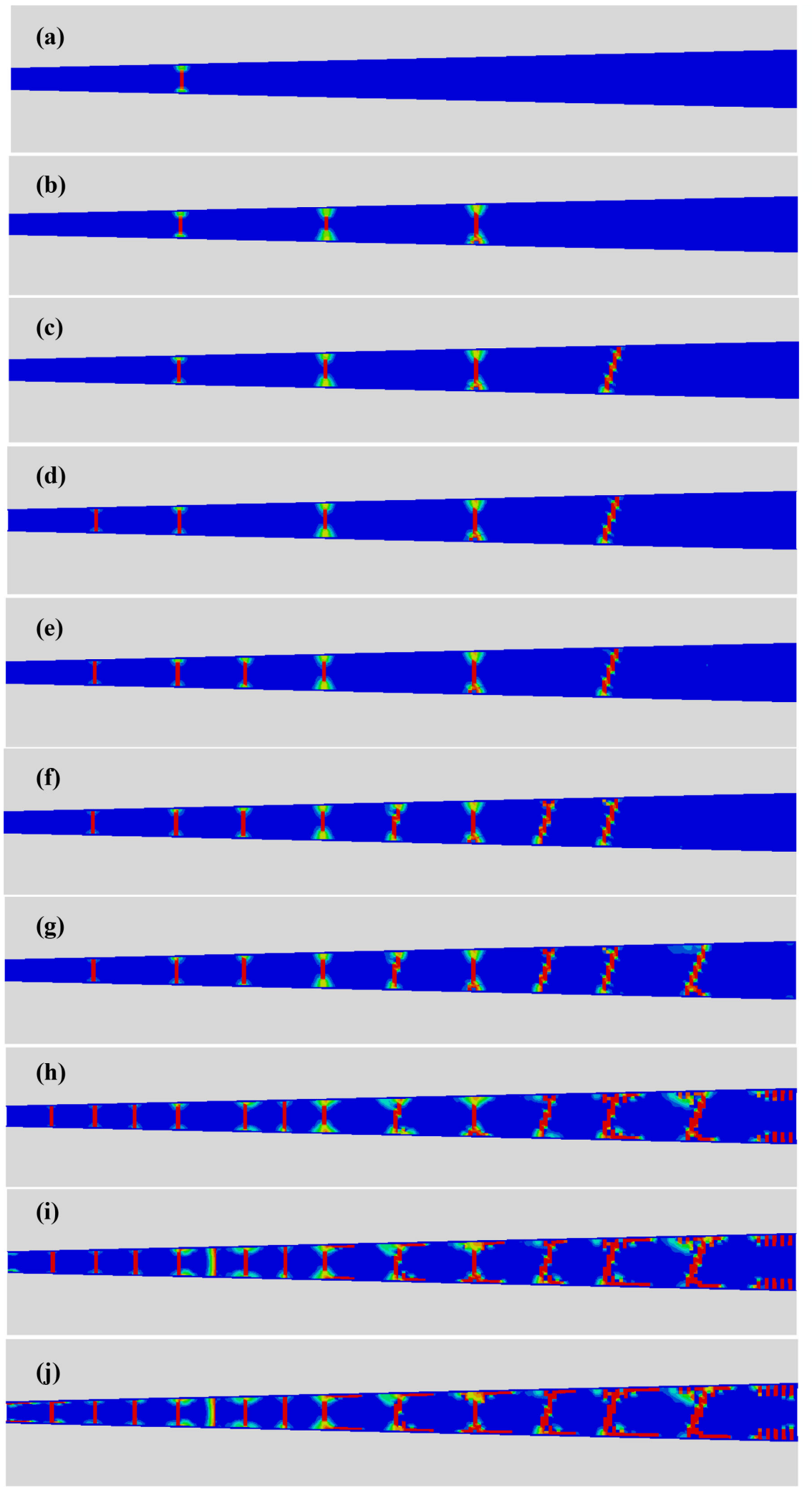

Figure 10. Cracking process for pattern I for $\alpha=3.0$. The interface shear strength is higher than the threshold, and vertical cracking and interface-parallel cracking can be observed.

cracks, the tensile stress near the middle location along the path always reaches its peak value, so new crack initiates at this location. It can also be found that the peak tensile stresses between adjacent cracks decreases gradually as their locations are gradually away

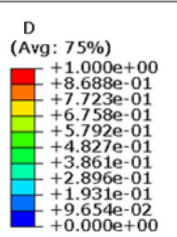

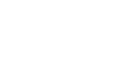

from the left-hand side (Figs 13a and c). This is the reason that the infilling cracks appear first in the thin parts of cracked layer and then in the thick parts. It can also be found that the peak shear stresses increase as the corresponding locations are away from the 


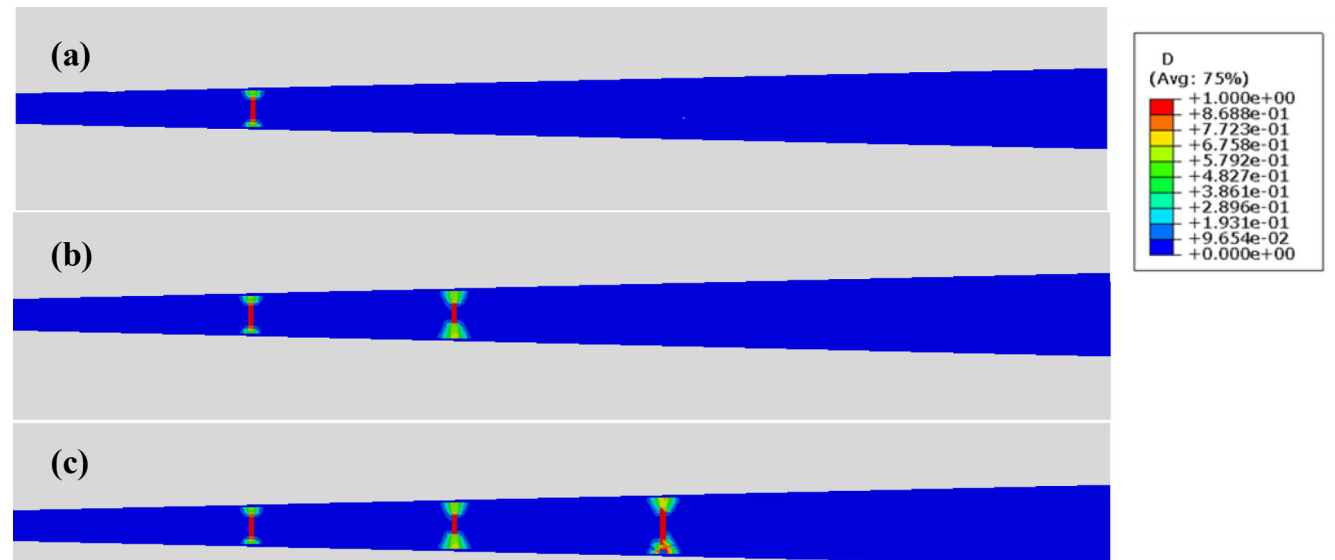

(d)

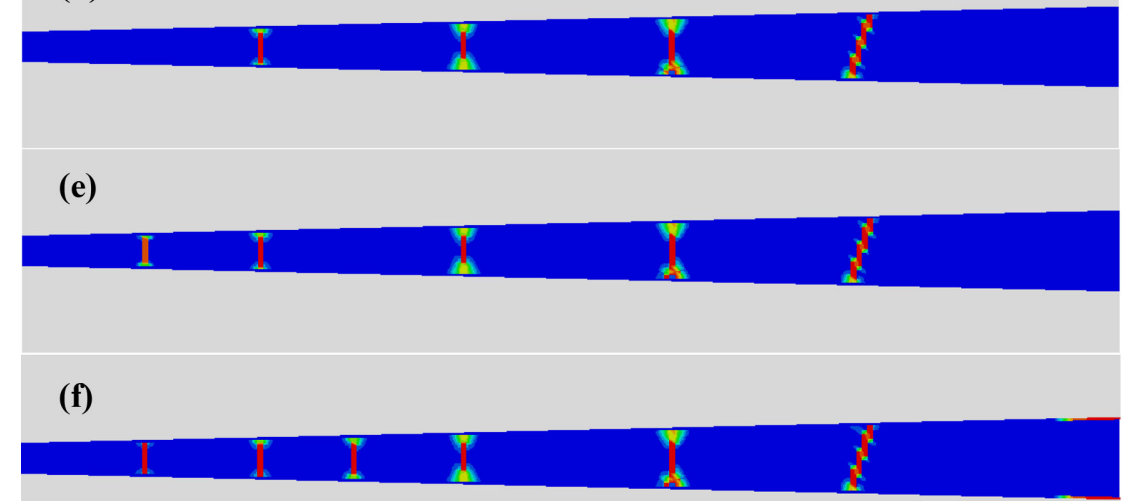

(g)

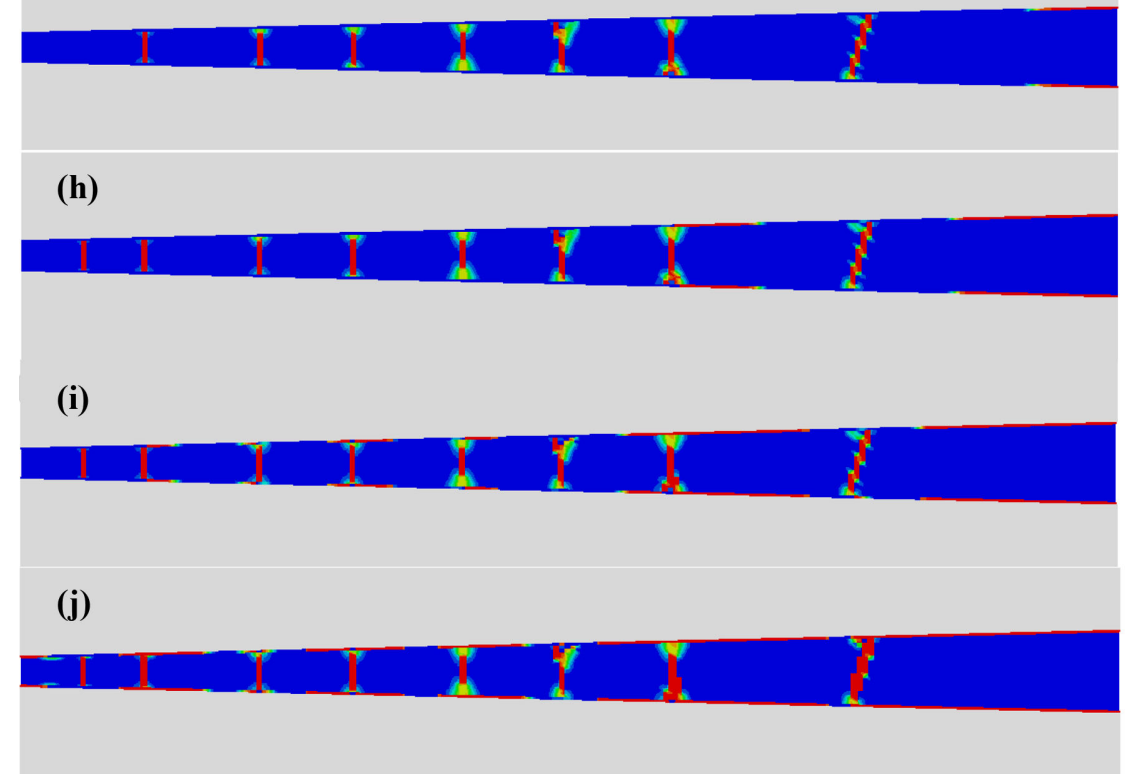

Figure 11. Cracking process for pattern II for $\alpha=3.0$. The interface shear strength is less than the threshold, and vertical cracking and interfacial delamination can be observed.

left-hand side (Figs 13b and d). Therefore, the interface-parallel cracks first appear in the thick parts of the cracked layer and then in the thin parts. If vertical cracks form, the tensile load in the interlayer is transmitted from the top and bottom layers through the interfaces. Once interface-parallel cracks form, the load from the adjacent layers cannot be transmitted effectively. As a result, the tensile stress and the interfacial shear stress drop to a lower level (as indicated in Figs 13e and 12f). 


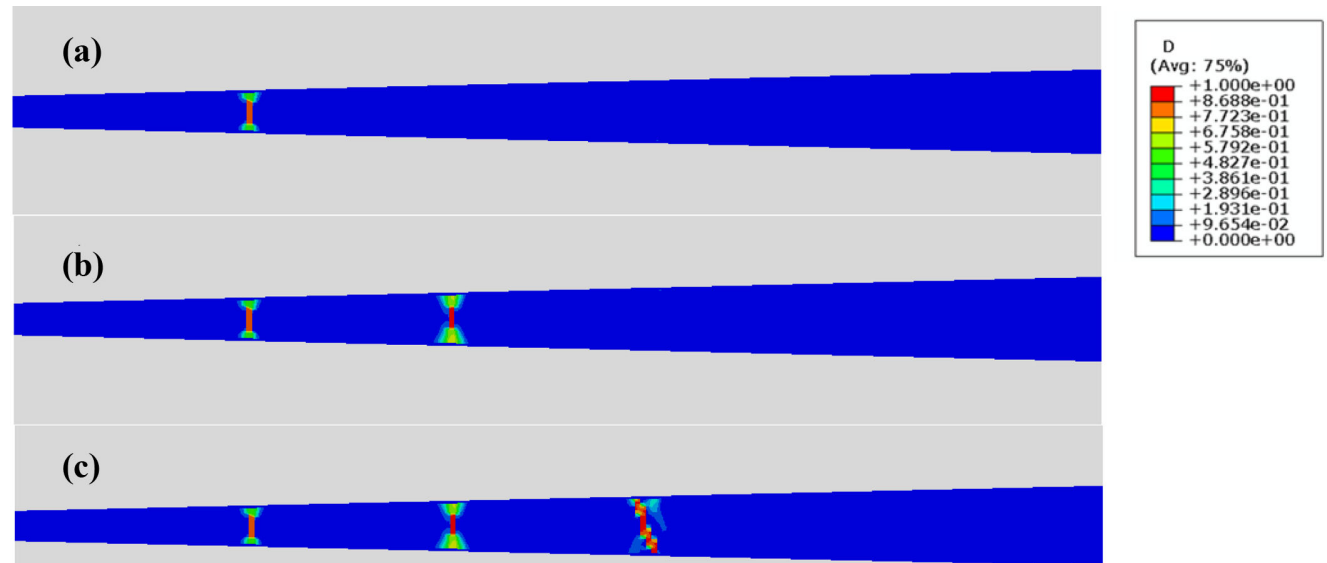

(d)

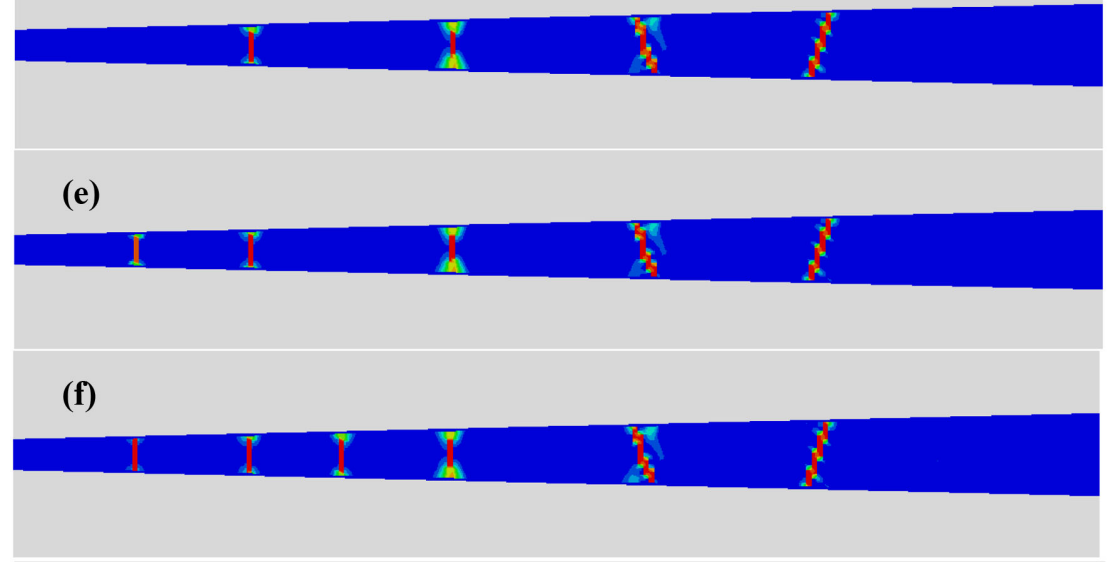

(g)

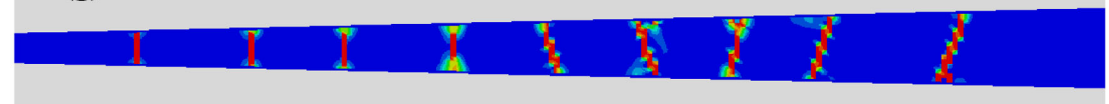

(h)

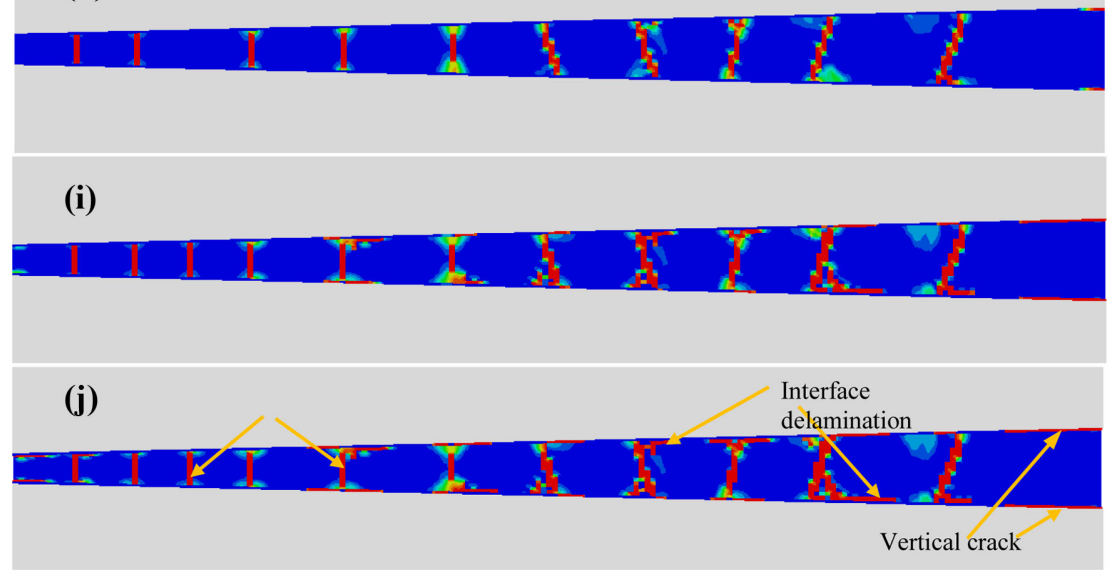

Figure 12. Cracking process for pattern III for $\alpha=3.0$. The interface shear strength is close to the threshold, and vertical cracking, interface-parallel cracking and interface delamination can be observed.

The evolutions of the stresses for pattern II are similar to those of pattern I during the vertical crack infilling process, as presented in Fig. 14. For this case, the interfacial delamination can be observed due to the lower interface shear strength. It can be seen from Fig. 14(a) that peak tensile stresses between adjacent cracks decreases gradually as their locations are gradually away from the left-hand side. One can conclude that from Fig. 14(a) that the infilling crack must appear first at location A and then at location B. 


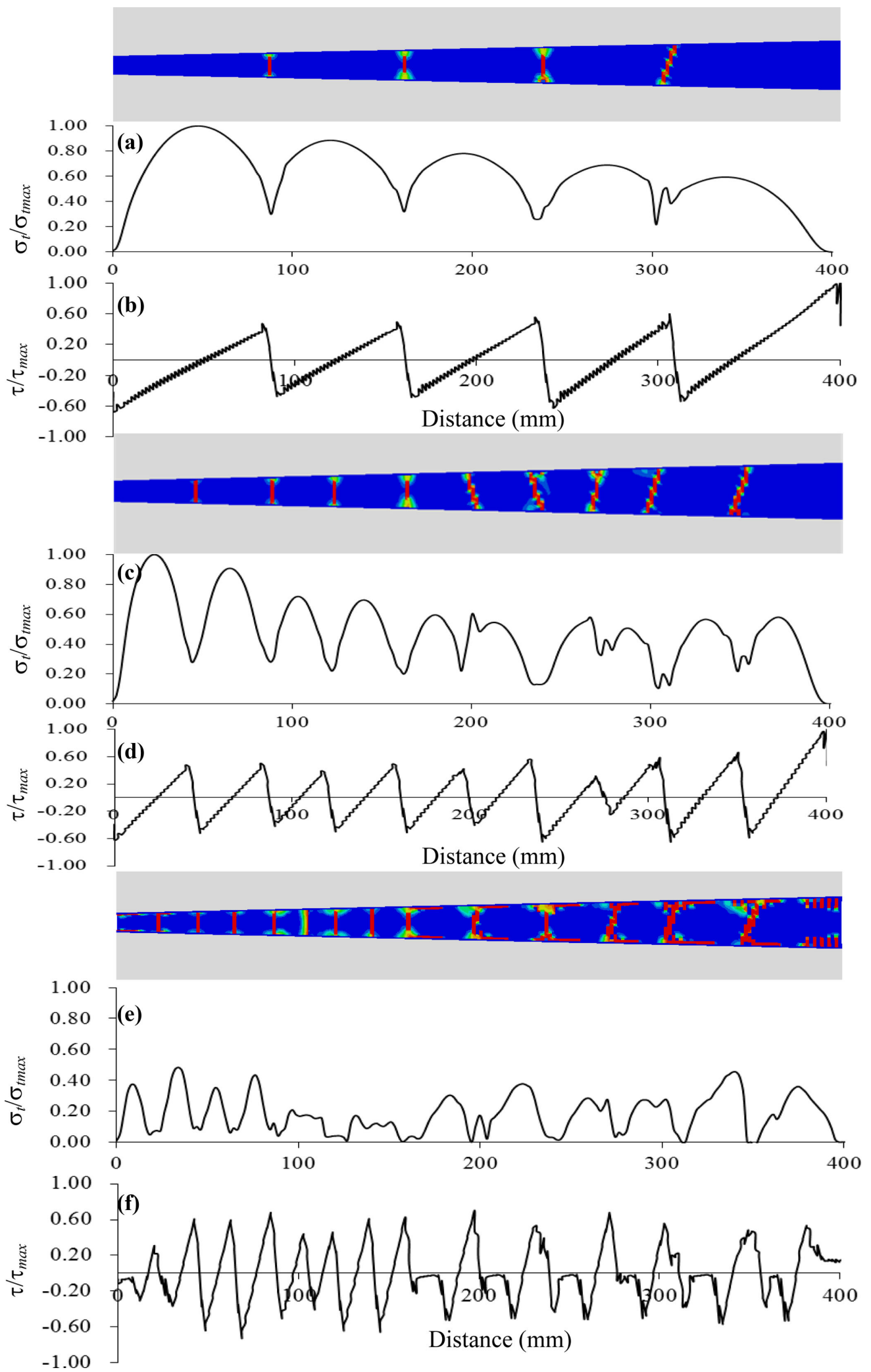

Figure 13. Evolution of tensile stress along the path and interfacial shear stress for pattern I for $\alpha=3.0$.

According to Fig. 14(c), the peak tensile stresses and locations A and $\mathrm{B}$ drop to lower levels once the infilling cracks initiate. As a result, the third infilling crack will appear at location $\mathrm{C}$. Therefore, the infilling cracks can lead to the stress redistribution and the peak tensile stress moves from thin parts to the thick parts. Similar to those of pattern I, interfacial shear stresses in thick parts are higher than those in thin parts (Figs $14 \mathrm{~b}$ and c). The interfacial delamination therefore first forms in the thick parts and then in the thin parts. The interfacial delamination can reduce the load from the adjacent layers and thus further decrease the tensile and shear stresses 

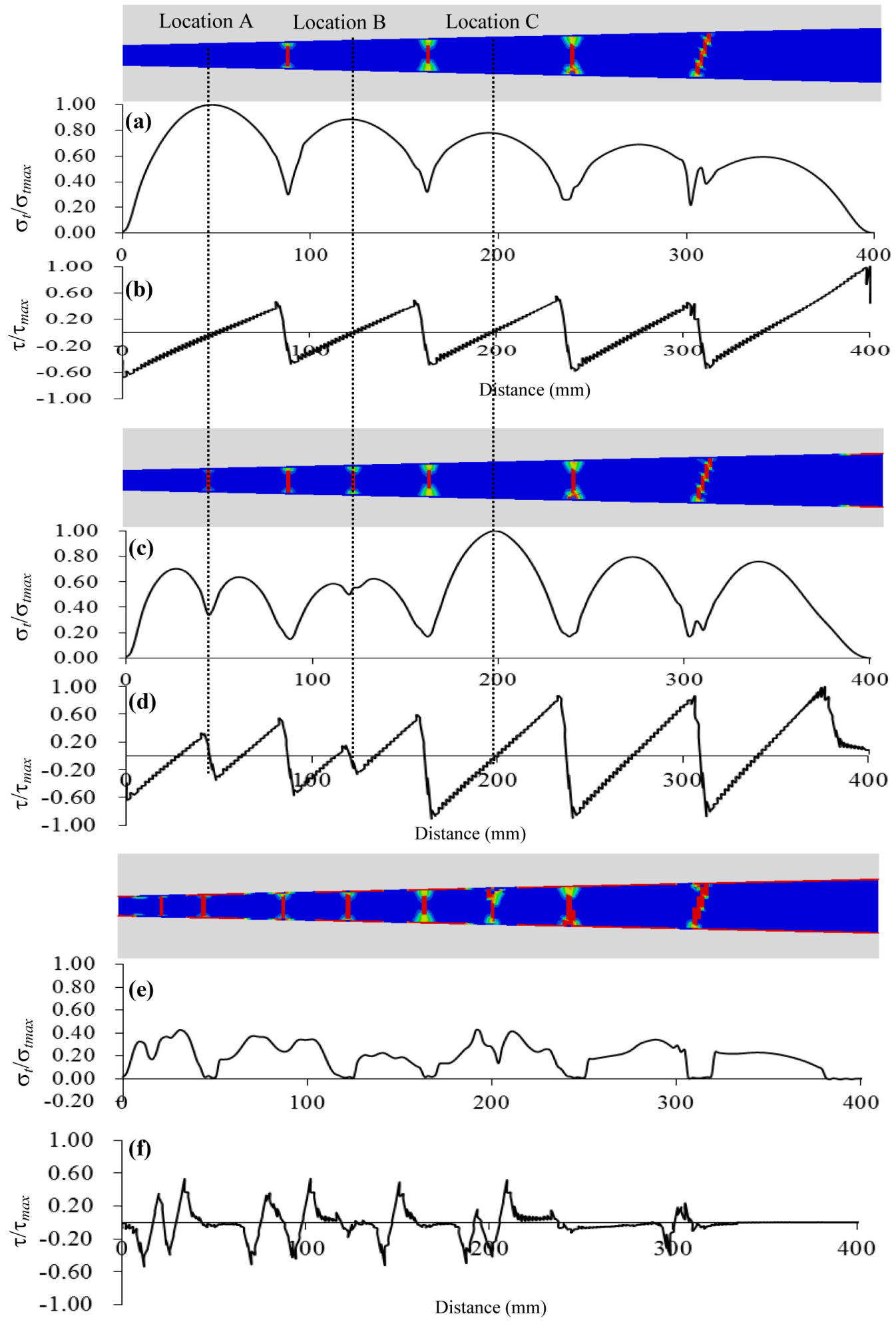

Figure 14. Evolution of tensile stress along the path and interfacial shear stress for pattern II for $\alpha=3.0$.

(Figs $14 \mathrm{e}$ and $\mathrm{f}$ ). As a result, the further infilling of the vertical cracks are excluded (Fig. 14f).

For case III, the evolutions of the tensile and shear stresses are presented in Fig. 15. One could find both interfacial delamination and interface-parallel cracking will decrease the stress along the path and interfacial stress and thus exclude the further infilling of the vertical cracks.

\subsection{Influence factors}

\subsubsection{Variation coefficient of layer thickness}

The variation coefficient of layer thickness is discussed in this section. Three different coefficients, $\alpha=1.0,3.0$ and 9.0, are adopted in this section to investigate its influences. Other input data are the same as those listed in Table 2. The crack patterns 

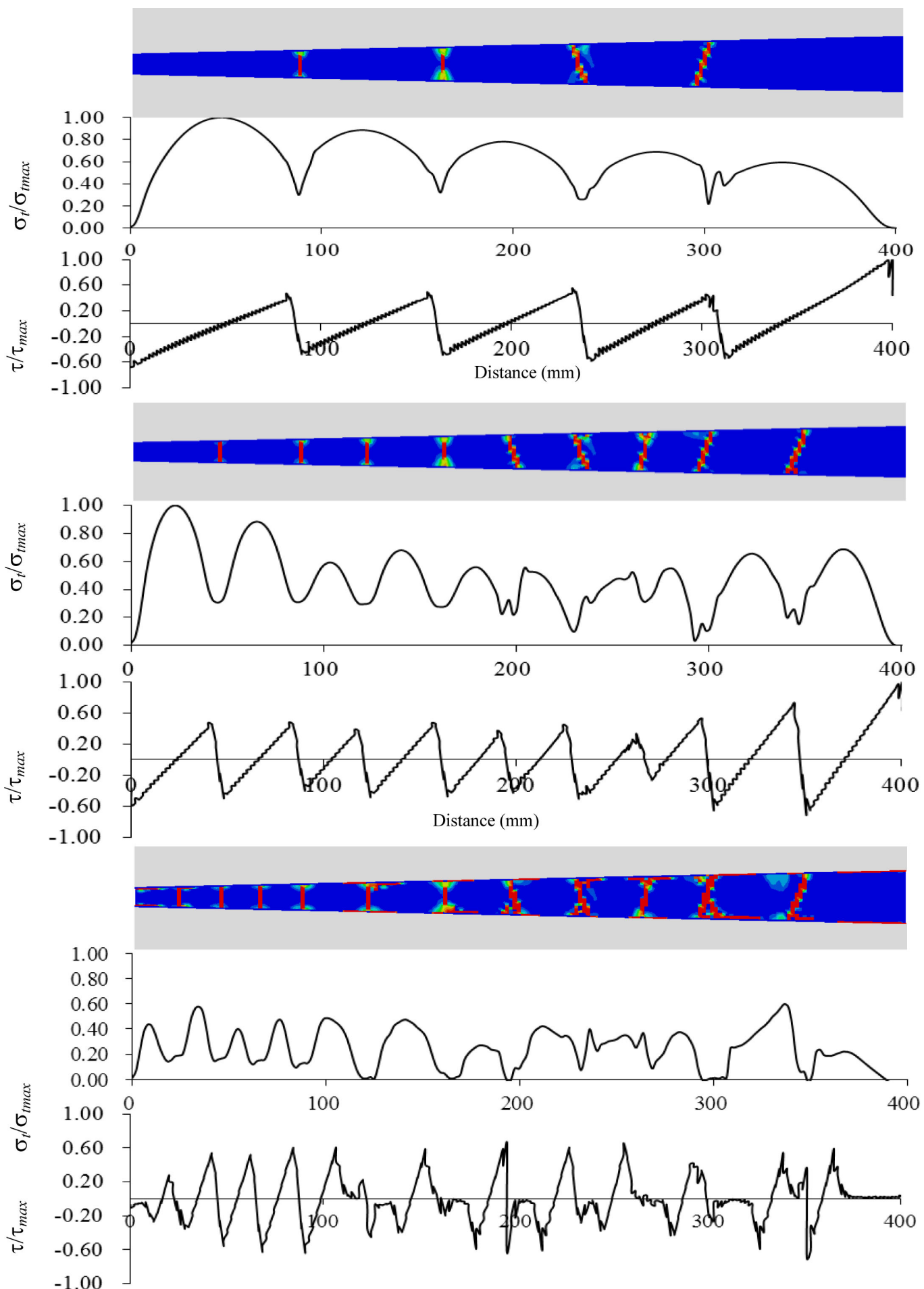

Figure 15. Evolution of tensile stress along the path and interfacial shear stress for pattern III for $\alpha=3.0$.

of the three-layer system with different coefficients are presented in Fig. 16. It can be seen that the typical crack patterns mentioned above also can be found for $\alpha=9.0$. For each typical crack pattern, the number of crack increases by increasing the coefficient, $\alpha$.

From the discussion mentioned above, one can find that these vertical cracks in a system with constant layer thickness are equally spaced. However, in a system with varying layer thickness, the crack spacings are quite different. To simplify the discussion, the average crack spacing $\left(S_{\mathrm{a}}\right)$ at saturation are used, which are defined as

$S_{\mathrm{a}}=L /(n-1)$

where is the length of the layered system and $n$ is the number of vertical crack.

The influences of the variation coefficient of layer thickness, $\alpha$, on the average fracture spacing to layer thickness ratios at saturation $\left(S_{\mathrm{a}} / T\right)$ for the typical cracking patterns are plotted in Fig. 17. It can be seen that, for each case, $S_{\mathrm{a}} / T$ decreases by increasing the 

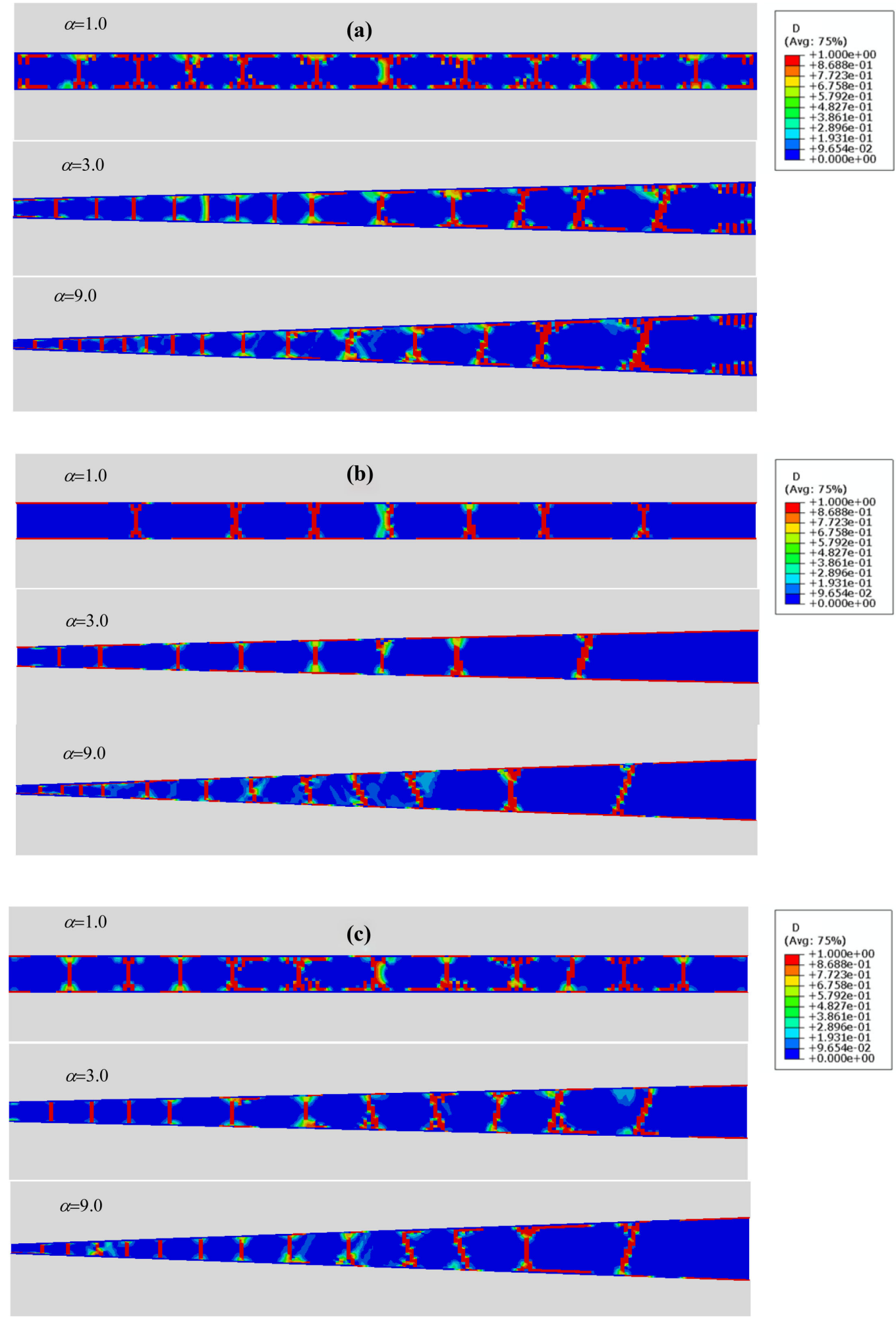

Figure 16. Influences of the variation coefficient of layer thickness, $\alpha$, on the crack patterns. (a) pattern I; (b) pattern II and (c) pattern III.

variation coefficient of layer thickness, $\alpha$. At a given $\alpha, S_{\mathrm{a}} / T$ for the pattern II is much higher than those for other patterns.

\subsubsection{Overburden pressure}

As mentioned above, there exists a threshold for the interface shear strength, which controls the crack patterns of the layered system. To explore the overburden influence on the threshold, different pressures in the vertical direction are used, while other parameters keep constant. As plotted in Fig. 18, the thresholds for both cases $(\alpha=1.0$ and 3.0) decrease by increasing the overburden pressure. At a given overburden pressure, the threshold for $\alpha=1.0$ is higher than that for $\alpha=3.0$. 


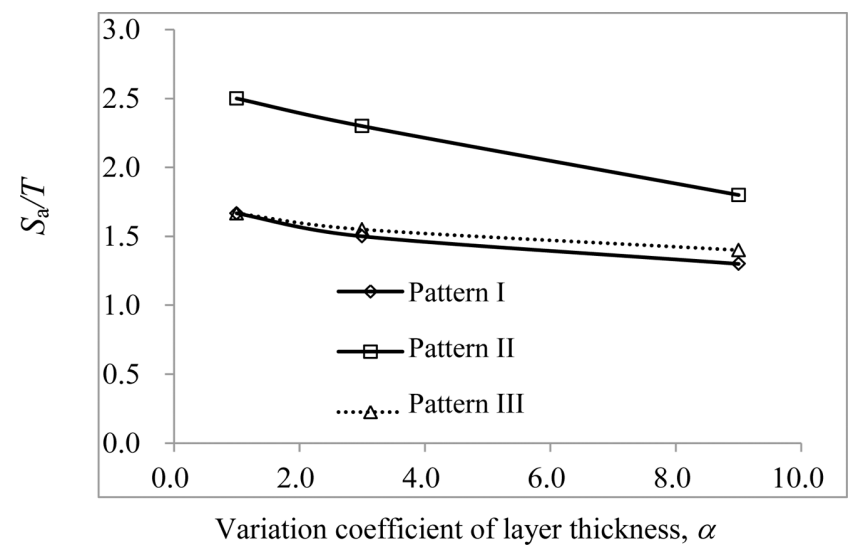

Figure 17. Variation coefficient of the layer thickness on the crack spacing to average layer thickness ratio at saturation.

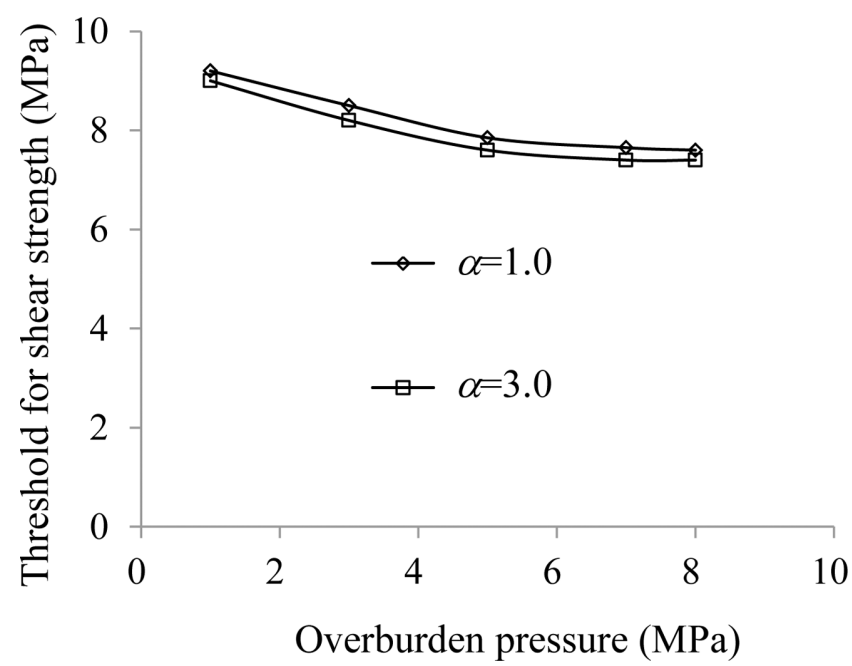

Figure 18. Influences of the overburden pressure on the threshold for interface shear strength.

\subsubsection{Rock strength}

The rock tensile strength for the interlayer increases from 2 to $15 \mathrm{MPa}$, while the material parameters for the bottom and top layers remain constant. In addition, $\alpha=3.0$ is adopted. For a given strength, the interfacial strength is varied until its threshold is obtained. The relationship between the tensile strength and the threshold is shown in Fig. 19. One can find from the figure that the threshold increases by increasing interlayer strength.

\section{DISCUSSION}

The earlier theoretical explanations for the cracking saturation are based on the full-slip, or frictional coupling model between layers (Price 1966; Hobbs 1967). These works tend to oversimplify the stress distributions between two adjacent cracks as linearity and fail to obtain the evolution of stress state during the cracking process. In the latest studies, Bai et al. (2000) and Tang et al. (2008) indicate that the crack spacing is so small that compressive state arises in a crack-bound block, and thus new tensile crack cannot further infill. It should be noted that the layers are assumed to be bonded well together in their models and the failure between layers are not considered. The numerical simulation based on the damaged model for rocks and CZM for interfaces in this study can capture the interface failure and rock cracking. The stress evolution in this study indicates

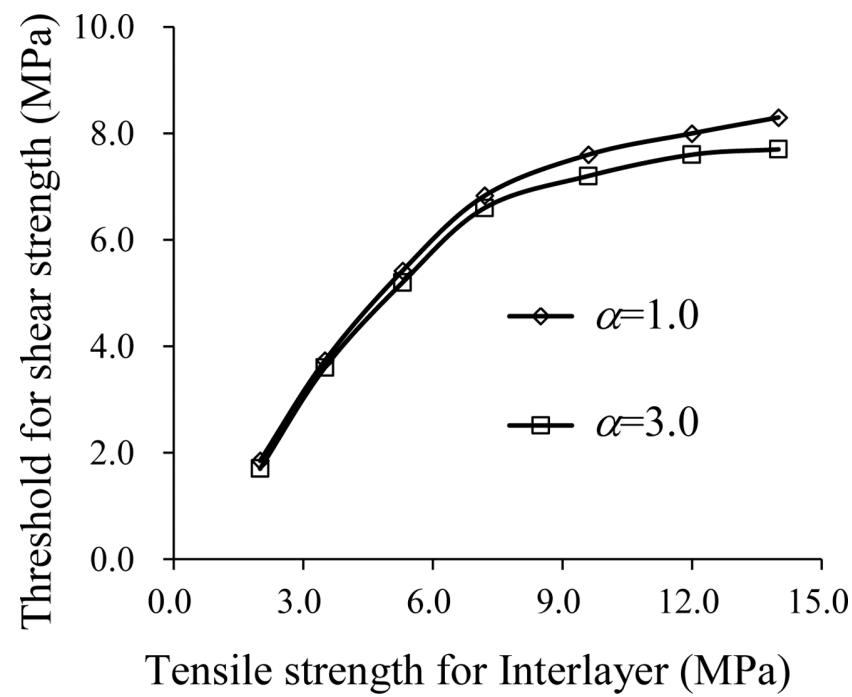

Figure 19. Influences of the tensile strength for the interlayer on the threshold for interface shear strength.

that the interface-parallel cracking and the interfacial delamination can decrease the tensile and shear stress between two adjacent vertical cracks. As a result, the loading cannot be transmitted effectively from the adjacent layers. Therefore, the interface delamination and interface-parallel cracking can also result in saturation in addition to crack spacing.

The interface-parallel discontinuities have been mentioned in many existing studies (Thouless 1989; Cherepanov 1994; Li et al. 2012) and are generally called 'delamination'. However, the layers are assumed to be bonded well together in their studies. This means that interface delamination is excluded, and the so-called delamination might be the interface-parallel cracking. According to the crack patterns described in this study, these parallel discontinuities may be induced by interface delamination, interface-parallel cracks, or their coupling behaviour. The interface delamination always occurs if the interface shear strength is lower. The formation of the interface delamination can reduce the load from the adjacent layers and thus prevent or delay the further infilling of vertical cracks. The interfaceparallel cracking occurs at a higher interface shear strength. As a result, the interface delamination produces wider crack spacing because it happens earlier than layer-parallel fracturing. This may provide a method to discriminate interface delamination from interfaceparallel cracking. It should be noted that the interface-parallel cracks obtained in this numerical simulation need to be further validated in the fields.

\section{CONCLUSIONS}

A better understanding of the crack spacing problem in layered rock contributes to geological prospecting and safety design of underground structures. In this study, the formation mechanisms for the interface-parallel discontinuities and their interaction with vertical cracks in layered rock with varying thickness are discussed qualitatively.

(1) The crack patterns of the layered rocks are controlled by the interface strength. If the strength is greater than a threshold, the vertical cracks and interface-parallel cracks can initiate and develop, whereas the interlayer is meshed by vertical cracks combined with delamination if the strength is less than the 
critical one. If the strength is close to the threshold, a combined pattern of vertical cracking, interface-parallel cracking and delamination occurs. The interface-parallel discontinuities are induced by interfacial delamination, interface-parallel cracks or their coupling behaviours.

(2) The cracking process for the system with constant layer thickness and system with varying layer thickness are quite different. For the system with constant layer, the vertical cracks and discontinuities appear symmetrically. For the system with varying layer thickness, the vertical cracks form in sequence, first in the thin parts of layers and then in the thick parts and parallel discontinuities appear first in the thick parts and then in the thin parts. For the system with constant layer thickness, no vertical cracks can further infill during the formation of parallel discontinuities. However, the infilling cracks and interface-parallel cracks can appear simultaneously for the system with varying layer thickness.

(3) The interfacial delamination and interface-parallel cracking can change the stress distribution between two adjacent cracks. If no delamination and interface-parallel cracking occurs, the peak tensile stress between two adjacent vertical cracks decreases gradually as the interlayer thickness increases. The infilling crack can reduce the tensile stress between two adjacent cracks. Therefore, as the infilling cracks appear continuously, the peak tensile stress moves from the thin parts to the thick parts of the interlayer. The interfaceparallel cracking and interface delamination can reduce the tensile stress between two adjacent cracks and thus delay or exclude further vertical crack infilling.

(4) The parametric study indicates that the average crack spacing to layer thickness ratio at saturation decreases by increasing the variation coefficient of layer thickness. The overburden pressure and rock strength can greatly influence the threshold for interface shear strength, which determines the fracture pattern of the layered system.

\section{ACKNOWLEDGEMENTS}

This study was fully supported by National Natural Science Fund of China (project nos 51304067 and 51674100) and the Fundamental Research Funds for the Universities of Henan Province (project no. NSFRF140206) and the Distinguished Young Scholars of Henan Polytechnic University (project no. J2015-1).

\section{REFERENCES}

ABAQUS, 2009. ABAQUS 6.9 Analysis Manual, ABAQUS, Inc., Providence, RI.

Areias, P., Rabczuk, T. \& Camanho, P., 2016. Finite strain fracture of 2D problems with injected anisotro-pic softening elements, Theor. Appl. Fract. Mech., 72, 50-63.

Bai, T., Pollard, D.D. \& Gao, H., 2000. Explanation for fracture spacing in layered materials, Nature, 403, 753-756.

Chang, X., Yan, A.Z. \& Liao, M.C., 2011. Analysis of periodic cracks in surface layer of pavement structures, Eng. Fail. Anal., 18, 411-420.

Cherepanov, G.P., 1994. On the theory of thermal stresses in a thin film on a ceramic substrate, J. appl. Phys., 75, 844-849.

Dugdale, D., 1960. Yielding of steel sheets containing slits, J. Mech. Phys. Solids, 8, 100-104.
Engelder, T., Lash, G.G. \& Uzcátegui, R.S., 2009. Joint sets that enhance production from middle and upper devonian gas shales of the appalachian Basin, AAPG Bull., 93(7), 857-889.

Ferrill, D.A., Morris, A.P., McGinnis, R.N., Smart, K.J. \& Ward, W.C., 2011. Fault zone deformation and displacement partitioning in mechanically layered carbonates: the Hidden Valley fault, central Texas, AAPG Bull., 95, 1383-1397.

Ferrill, D.A., Morris, A.P. \& McGinnis, R.N., 2012. Extensional faultpropagation folding in mechanically layered rocks: the case against the frictional drag mechanism, Tectonophysics, 5, 78-85.

Gross, M.R. \& Engelder, T., 1995. Fracture strain in adjacent units of the Monterey Formation: scale effects and evidence for uniform displacement boundary conditions, J. Struct. Geol., 17, 1303-1318.

Gudmundsson, A., Guidi, G.D. \& Scudero, S., 2013. Length-displacement scaling and fault growth, Tectonophysics, 608, 1298-1309.

Hobbs, D.W., 1967. The formation of tension joints in sedimentary rock: an explanation, Geol. Mag., 104(6), 550-556.

Hooker, J.N., Laubach, S.E. \& Marrett, R., 2013. Fracture-aperture sizefrequency, spatial distribution, and growth process in strata-bounded and non-strata-bounded fractures, Cabrian Meson Group, NW Argentina, J. Struct. Geol., 54, 54-71.

Hooker, J.N., Gale, J.F.W., Gomez, L.A., Laubach, S.E., Marrett, R. \& Reed, R.M., 2009. Aperture-size scaling variations in a low-strain opening-mode fracture set, Cozzette Sandstone, Colorado, J. Struct. Geol., 31, 707-718.

Hooker, J.N. \& Katz, R.F., 2015. Vein spacing in extending layered rocks: the effect of synkinematic cementation, Am. J. Sci., 315, 557-588.

Jesus, A.P., Mateus, A., Munhá, J.M., Tassinari, C.C.G., Santos, T.M.B. \& Benoif, M., 2016. Evidence for under plating in the genesis of the Variscan synorogenic Beja Layered Gabbroic Sequence and related mesocratic rocks, Tectonophyics, 683, 148-171.

Li, Y. \& Yang, C., 2007. On fracture saturation in layered rocks, Int. J. Rock Mech. Min., 44, 936-941.

Li, L.C., Tang, C.A. \& Wang, S.Y., 2012. A numerical investigation of fracture infilling and spacing in layered rocks subjected to hydro-mechanical loading, Rock Mech. Rock Eng., 45, 753-765.

Lubliner, J., Oliver, J., Oller, S. \& Oñate, E., 1989. A plastic damage model for concrete, Int. J. Solids Struct., 25, 299-329.

Noten, K.V. \& Sintubin, M., 2010. Linear to non-linear relationship between vein spacing and layer thickness in centimeter- to decimeter-scale siliciclastic multilayers from High-Ardenne slate belt (Belgium, Germany), J. Struct. Geol., 32, 377-391.

Oded, R., 2008. Delamination analysis of fiber-reinforced-polymer strengthened beams: cohesive zone modeling versus a linear elastic fracture mechanics approach, Eng. Fract. Mech., 75, 2842-2859.

Price, N.J., 1966. Fault and Joint Development in Brittle and Semi-Brittle Rocks, Pergamon Press, p. 176.

Riley, P., Tikoff, B. \& Murray, A.B., 2011. Quantification of fracture networks in non-layered, massive rock using synthetic and natural data sets, Tectonophysics, 505, 44-56.

Shcherbakov, R. \& Turcotte, D.L., 2003. Damage and self-similarity in fracture, Theor. Appl. Fract. Mech., 39, 245-258.

Tang, C.A. et al., 2008. Fracture spacing in layered materials: a new explanation based on two-dimensional failure process modelling, Am. J. Sci., 308, 49-72.

Thouless, M.D., 1989. Some mechanics for the adhesion of thin films, Thin Solid Films, 181, 397-406.

Wu, H. \& Pollard, D.D., 1995. An experimental study of the relationship between joint spacing and layer thickness, J. Struct. Geol., 17, 887-905.

Wang, J., 2006. Cohesive zone model of intermediate crack-induced delamination of FRP- plated concrete beam, Int. J. Solids Struct., 43, 6630-6648.

Zhang, X. \& Jeffrey, R.G., 2006. The role of friction and secondary flaws on deflection and re-initiation of hydraulic fractures at orthogonal preexisting fractures, Geophys. J. Int., 166, 1454-1465. 